This item was submitted to Loughborough's Research Repository by the author.

Items in Figshare are protected by copyright, with all rights reserved, unless otherwise indicated.

\title{
A comparison of braking and differential control of road vehicle yaw-sideslip dynamics
}

PLEASE CITE THE PUBLISHED VERSION

PUBLISHER

Professional Engineering Publishing / @ IMechE

VERSION

VoR (Version of Record)

LICENCE

CC BY-NC-ND 4.0

\section{REPOSITORY RECORD}

Hancock, P.J., R.A. Williams, T.J. Gordon, and Matt C. Best. 2009. "A Comparison of Braking and Differential Control of Road Vehicle Yaw-sideslip Dynamics". figshare. https://hdl.handle.net/2134/5113. 
This item was submitted to Loughborough's Institutional Repository (https://dspace.lboro.ac.uk/) by the author and is made available under the following Creative Commons Licence conditions.

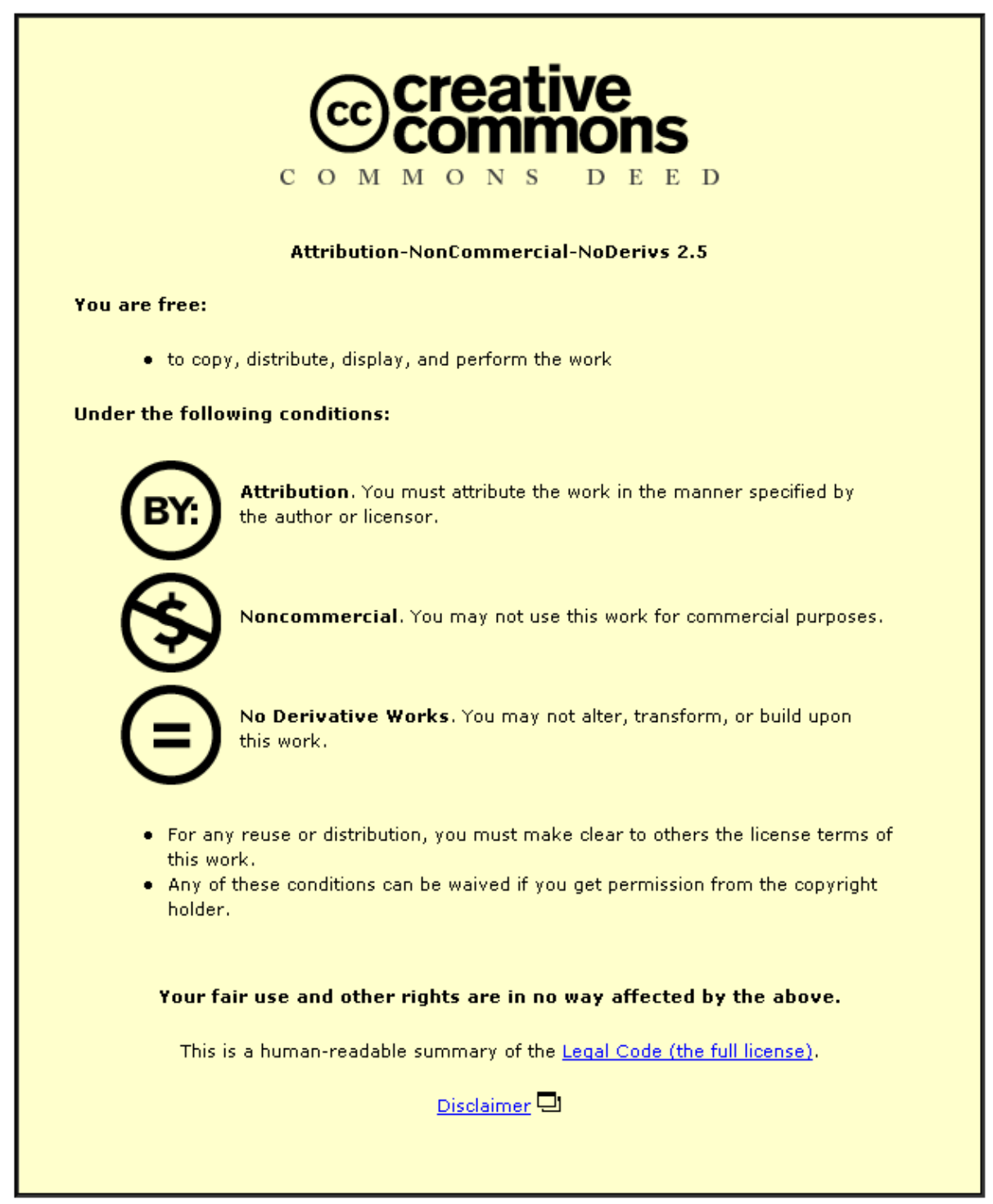

For the full text of this licence, please go to: http://creativecommons.org/licenses/by-nc-nd/2.5/ 


\title{
A comparison of braking and differential control of road vehicle yaw-sideslip dynamics
}

\author{
M J Hancock ${ }^{1 *}$, R A Williams ${ }^{1}$, T J Gordon ${ }^{2}$, and M C Best ${ }^{2}$ \\ ${ }^{1}$ Engineering Centre, Jaguar Cars Limited, Coventry, UK \\ ${ }^{2}$ Department of Aeronautical and Automotive Engineering, Loughborough University, Loughborough, UK
}

The manuscript was received on 10 July 2003 and was accepted after revision for publication on 22 September 2004.

DOI: 10.1243/095440705X6721

\begin{abstract}
Two actuation mechanisms are considered for the comparison of performance capabilities in improving the yaw-sideslip handling characteristics of a road vehicle. Yaw moments are generated either by the use of single-wheel braking or via driveline torque distribution using an overdriven active rear differential. For consistency, a fixed reference vehicle system is used, and the two controllers are synthesized via a single design methodology. Performance measures relate to both open-loop and closed-loop driving demands, and include both on-centre and limit handling manoeuvres.
\end{abstract}

Keywords: vehicle dynamics, yaw-sideslip control, controlled differentials, vehicle modelling, active chassis systems

\section{INTRODUCTION}

Electronic traction and stability control systems are becoming standard fitment on top end performance motor vehicles. The majority of such systems currently in production utilize throttle and brake intervention apportion driving torques at each of the wheels with the aim of improving traction or developing a yaw moment that will improve vehicle stability. In this study the relative capabilities of controlled limited slip differentials (LSD) are investigated.

The ability of the limited slip differential to improve traction is relatively well documented [1-3]. However, recent advances in differential design have opened up the possibility of controlled differentials being used in the field of active vehicle dynamics [4]. As yet, the extent of the capabilities of controlled differentials in this field is not widely appreciated. For example, it is unclear whether they could replace or simply augment brake intervention based or active brake control (ABC) systems. However, it would appear likely that such devices may have an inherent advantage over $\mathrm{ABC}$ because they operate by directly

\footnotetext{
* Corresponding author: Jaguar Research, Engineering Centre, Jaguar Cars Limited, Whitley, Coventry, CV3 4LF, UK. email: mhancoc1@jaguar.com
}

reapportioning the torque supplied to the wheels. The ABC system on the other hand can only reduce torque and therefore cannot operate without slowing the vehicle down and therefore tends to be restricted to limit handling scenarios.

There are many examples of controlled differential systems in the literature. The vast majority employ an LSD similar to the passive gerodisc type [5] where a friction clutch is employed effectively to provide a connection between the two driveshafts. The distinguishing feature of this type of LSD is that it will always transfer torque to the slower wheel. Such control systems thus have no control over the direction of torque transfer and are only able to modulate the magnitude that is being applied. The general objective is therefore to emulate and optimize the positive aspects of passive LSD performance while eliminating the negative aspects $[2,6]$.

The advent of the 'overdriven' differential [4, 7], however, makes it possible to control both the magnitude and direction of torque transfer. This allows the direction of the resulting yaw moment to be controlled and has led to the development of active yaw control systems $[\mathbf{7}, \mathbf{8}]$ which utilize controlled torque transfer. Details of the full capabilities of such systems are scarce, however. In one case an attempt has been made to integrate a yaw control system with a brake intervention based stability 
control system, but the relative merits of the two systems and the benefits gleaned from integration are not discussed in great detail $[\mathbf{8}]$.

The present paper investigates the potential of an active overdriven differential to control the yaw moment of a vehicle and offers a comparison with a brake-based system.

\section{VEHICLE MODEL}

\subsection{Chassis model}

To facilitate the investigation, a vehicle handling model was created. The main features of this model are highlighted below (a more detailed description can be found in Appendix 2):

(a) four degrees of freedom (4DOF): longitudinal, lateral, yaw, and roll;

(b) rear-wheel drive;

(c) non-linear tyres (utilizes version 94 of the magic formula tyre model);

(d) longitudinal and lateral weight transfer;

(e) compliance in the steering system.

Note that aerodynamic drag and driveline dynamics are not included in the model (driving/braking torques are thus applied directly to the wheels). The SAE sign convention was employed and is used throughout this paper.

To facilitate the analysis of the behaviour of the vehicle model, a simple driver model was also employed. The objective of this model was to control the steering of the vehicle to follow any predefined trajectory as precisely as possible. The demanded trajectory is defined as a series of points, and the model operates by selecting the most appropriate 'target point' ahead of it using a variable preview system. A proportional, integral, and derivative (PID) controller then uses the error between the yaw angle required to reach this point and the actual yaw rate to give the required steering angle.

\subsection{Differential model}

A schematic of the type of overdriven differential considered in this paper is shown in Fig. 1. The differential uses two clutches $(\mathrm{Cl}$ and $\mathrm{Cr}$ in the schematic) to control the magnitude and direction of torque transfer between the driveshafts. If torque transfer to the left-hand wheel is desired, the lefthand clutch is engaged. If torque transfer to the right-hand wheel is desired, the right-hand clutch is

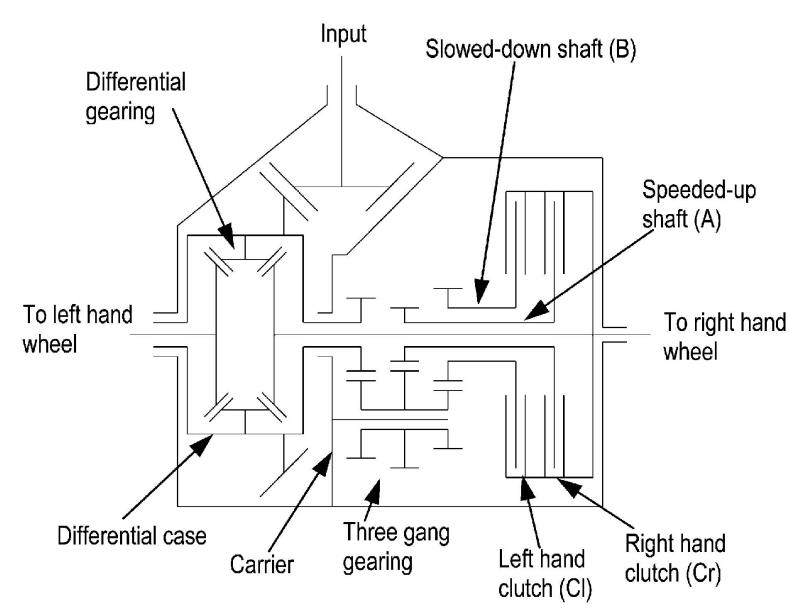

Fig. 1 Overdriven differential schematic

engaged. Provided a sufficient speed difference is present, the target torque transfer will be achieved (see section 3.4.1).

The relationship between the input torque, clutch torques, and driveshaft torques can be described as follows $[\mathbf{8}]$

$$
\begin{aligned}
& T_{1}=\frac{T_{\mathrm{i}}}{2}-\frac{z_{1} z_{5}}{2 z_{4} z_{2}} \Delta T_{\mathrm{cr}}+\frac{z_{1} z_{6}}{2 z_{3} z_{4}} \Delta T_{c l} \\
& T_{\mathrm{r}}=\frac{T_{\mathrm{i}}}{2}+\left(1-\frac{z_{1} z_{5}}{2 z_{4} z_{2}}\right) \Delta T_{\mathrm{cr}}-\left(1-\frac{z_{1} z_{6}}{2 z_{3} z_{4}}\right) \Delta T_{\mathrm{cl}}
\end{aligned}
$$

These relationships were used to represent an overdriven differential in the vehicle model, and their derivation is detailed in Appendix 3.

\section{CONTROLLER DESIGN}

In order to analyse the potential impact that controlled differentials can have on yaw-sideslip dynamics, it is firstly necessary to develop an appropriate yaw moment control algorithm.

\subsection{Design structure}

It was considered essential that the yaw moment controller be designed using a formal methodology, particularly in the light of the planned comparison with ABC. Such an approach was intended to ensure that a meaningful evaluation of the abilities of the actuator (and not the controller) could be made. To this end, linear optimal control theory was used to design a reference model based controller.

The design of the yaw moment controller is based on the methodology developed for a rear wheel steer control system [9]. Here, a linear quadratic 
regulator [10] (LQR) is applied to the non-linear vehicle model using a reference model controller. The controller is designed and applied at two different levels as illustrated in Fig. 2. The reference model is controlled by the primary feedback which is designed using cost functions describing the desired performance of the vehicle. However, since the reference model is linear, a secondary feedback (also designed using linear optimal control theory) is also required to minimize the errors between the vehicle and the reference model. Note that the primary feedback is also applied to the non-linear vehicle model, in addition to the reference model, to provide a feedforward element to the controller.

\subsection{Primary feedback}

\subsubsection{Reference model}

The reference model is a $2 \mathrm{DOF}$ linear yaw-sideslip model. The equation of motion for the lateral dynamics is

$$
F_{y \mathrm{f}}+F_{y \mathrm{r}}=M(\dot{V}+U r)
$$

A limited slip differential creates unequal left and right longitudinal forces, and so the equation of motion for yaw rotation is

$$
I_{z z} \dot{r}=b F_{y \mathrm{f}}-c F_{y \mathrm{r}}+\frac{t}{2} F_{x 1}-\frac{t}{2} F_{x \mathrm{r}}
$$

where

$$
F_{y \mathrm{f}}=C_{\alpha \mathrm{f}}\left(\delta_{\mathrm{d}}-\frac{V+b r}{U}\right)
$$

and

$$
F_{y \mathrm{r}}=C_{\alpha \mathrm{r}}\left(\frac{-V+c r}{U}\right)
$$

Also, assuming a uniform coefficient of friction

$$
\begin{gathered}
F_{x \mathrm{l}}=\frac{T_{\mathrm{i}}}{r_{\mathrm{r}}}+\frac{\Delta T}{r_{\mathrm{r}}} \\
F_{x \mathrm{r}}=\frac{T_{\mathrm{i}}}{r_{\mathrm{r}}}-\frac{\Delta T}{r_{\mathrm{r}}}
\end{gathered}
$$

where $T_{\mathrm{i}}$ is the input torque and $\Delta T$ is the torque transfer. Substituting equations (5) and (6) into equation (3) yields the following expression for the lateral dynamics

$$
M(\dot{V}+U r)=C_{\alpha \mathrm{f}}\left(\delta-\frac{V+b r}{U}\right)+C_{\alpha \mathrm{r}}\left(\frac{-V+c r}{U}\right)
$$

$$
\begin{aligned}
M(\dot{V}+U r)= & \left(\frac{-C_{\alpha \mathrm{f}}-C_{\alpha \mathrm{r}}}{U}\right) V \\
& +\left(\frac{-b C_{\alpha \mathrm{f}}+c C_{\alpha \mathrm{r}}}{U}\right) r+C_{\alpha \mathrm{f}} \delta_{\mathrm{d}}
\end{aligned}
$$

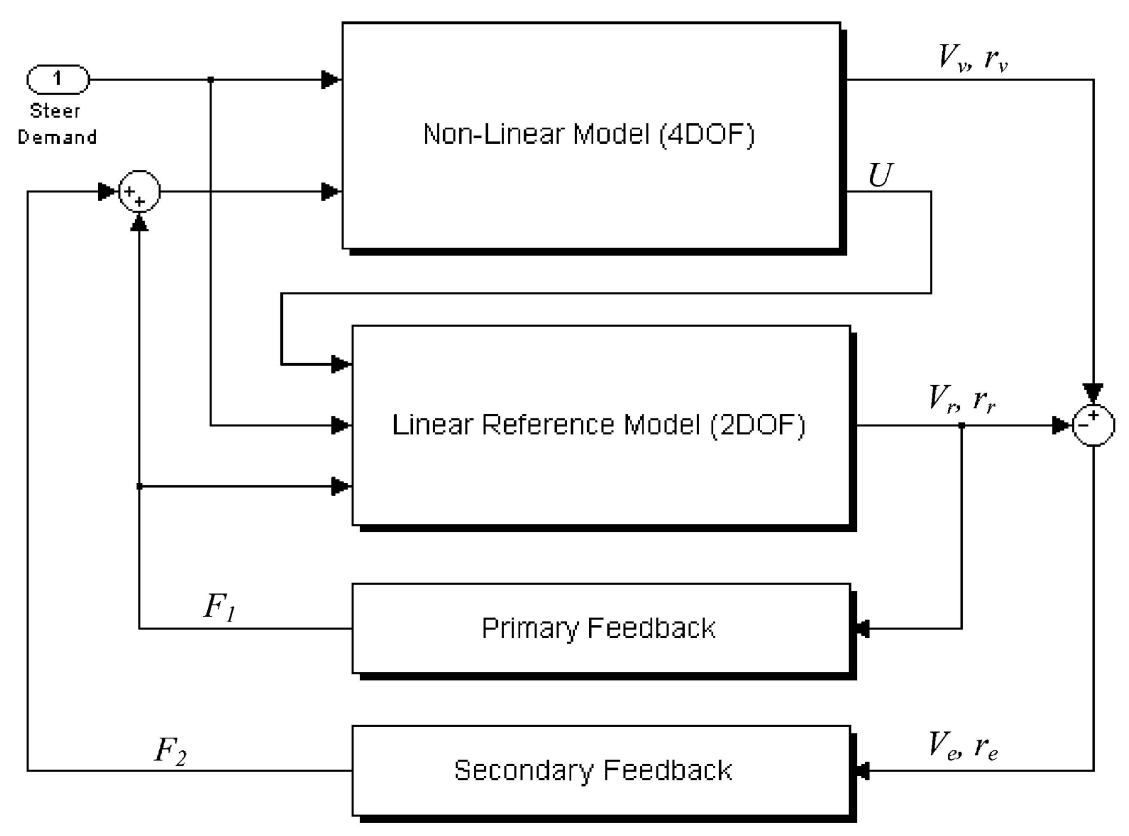

Fig. 2 Yaw moment controller structure 
which is of the form

$$
M(\dot{V}+U r)=Y_{V} V+Y_{r} r+Y_{\delta} \delta
$$

Similarly, substitution of equations (5) to (8) into equation (4) yields the following for the yaw dynamics

$$
\begin{aligned}
I_{z z} \dot{r}= & b C_{\alpha \mathrm{f}}\left(\delta-\frac{V+b r}{U}\right)-c C_{\alpha \mathrm{r}}\left(\frac{-V+c r}{U}\right) \\
& +\frac{t}{2}\left(\frac{T_{\mathrm{i}}}{r_{\mathrm{r}}}+\frac{\Delta T}{r_{\mathrm{r}}}\right)-\frac{t}{2}\left(\frac{T_{\mathrm{i}}}{r_{\mathrm{r}}}-\frac{\Delta T}{r_{\mathrm{r}}}\right) \\
I_{z z} \dot{r}= & \left(\frac{-b C_{\alpha \mathrm{f}}+c C_{\alpha \mathrm{r}}}{U}\right) V+\left(\frac{-b^{2} C_{\alpha \mathrm{f}}-c^{2} C_{\alpha \mathrm{r}}}{U}\right) r \\
& +b C_{\alpha \mathrm{f}} \delta_{\mathrm{d}}+\frac{t}{r_{\mathrm{r}}} \Delta T
\end{aligned}
$$

which is of the form

$$
I_{z z} \dot{r}=N_{V} V+N_{r} r+N_{\delta} \delta_{\mathrm{d}}+N_{\Delta T} \Delta T
$$

In state-space form, equations (11) and (14) may be written as follows

$$
\begin{aligned}
{\left[\begin{array}{c}
\dot{V} \\
\dot{r}
\end{array}\right]=} & {\left[\begin{array}{cc}
\frac{Y_{V}}{M} & \frac{Y_{r}}{M}-U \\
\frac{N_{V}}{I_{z z}} & \frac{N_{r}}{I_{z z}}
\end{array}\right]\left[\begin{array}{l}
V \\
r
\end{array}\right]+\left[\begin{array}{c}
0 \\
\frac{N_{\Delta T}}{I_{z z}}
\end{array}\right][\Delta T] } \\
& +\left[\begin{array}{c}
\frac{Y_{\delta}}{M} \\
\frac{N_{\delta}}{I_{z z}}
\end{array}\right]\left[\delta_{\mathrm{d}}\right]
\end{aligned}
$$

or

$$
\dot{X}=\mathbf{A} \boldsymbol{X}+\mathbf{B} \boldsymbol{u}+\mathbf{G} w
$$

which is a standard form with control input $\boldsymbol{u}=\Delta T$ and disturbance $\boldsymbol{w}=\delta_{\mathrm{d}}$.

\subsubsection{Problem posed by regulation}

In minimizing a proposed cost function, a regulator tends to drive all states to zero. This is clearly not acceptable in the case of the reference model described in the previous section, as the vehicle would simply be forced to drive in a straight line. The method proposed by Komatsu et al. [9] to address this problem was to include the demanded steer input, $\delta_{\mathrm{d}}$, as an additional state

$$
\begin{aligned}
{\left[\begin{array}{c}
\dot{\delta}_{\mathrm{d}} \\
\dot{V} \\
\dot{r}
\end{array}\right]=} & {\left[\begin{array}{ccc}
-0.0001 & 0 & 0 \\
\frac{Y_{\delta}}{M} & \frac{Y_{V}}{M} & \frac{Y_{r}}{M}-U \\
\frac{N_{\delta}}{I_{z z}} & \frac{N_{V}}{I_{z z}} & \frac{N_{r}}{I_{z z}}
\end{array}\right]\left[\begin{array}{c}
\delta_{\mathrm{d}} \\
V \\
r
\end{array}\right] } \\
& +\left[\begin{array}{c}
0 \\
0 \\
\frac{N_{\Delta T}}{I_{z z}}
\end{array}\right][\Delta T]
\end{aligned}
$$

The additional state is not controllable, but the use of a very slow decay rate makes it possible to stabilize the system, as is required by the LQR method [10]. This allows cost functions to be designed so that minimization will result in a desired steady state for any given $\delta_{\mathrm{d}}$. The states will still be driven to zero, but choosing a very slow first-order dynamic [as indicated in equation (17)] for $\delta_{\mathrm{d}}$ ensures that the system is regulated to settle into a steady state cornering condition.

During initial testing of the primary feedback design it became apparent that this representation of the driver's behaviour may be improved. As intimated above, equation (17) assumes that, following an initial input, the steering angle will effectively settle to a constant value. However, a more reasonable assumption would be that the driver continues with transient steering behaviour, and a second additional state, $\dot{\delta}_{\mathrm{d}}$, is therefore introduced as follows

$$
\begin{aligned}
{\left[\begin{array}{c}
\ddot{\delta}_{\mathrm{d}} \\
\dot{\delta}_{\mathrm{d}} \\
\dot{V} \\
\dot{r}
\end{array}\right]=} & {\left[\begin{array}{cccc}
-c_{\dot{\delta}} & 0 & 0 & -c_{r} \\
1 & 0 & 0 & 0 \\
0 & \frac{Y_{\delta}}{M} & \frac{Y_{V}}{M} & \frac{Y_{r}}{M}-U \\
0 & \frac{N_{\delta}}{I_{z z}} & \frac{N_{V}}{I_{z z}} & \frac{N_{r}}{I_{z z}}
\end{array}\right]\left[\begin{array}{c}
\dot{\delta}_{\mathrm{d}} \\
\delta_{\mathrm{d}} \\
V \\
r
\end{array}\right] } \\
+ & {\left[\begin{array}{c}
0 \\
0 \\
0 \\
\frac{N_{\Delta T}}{I_{z z}}
\end{array}\right][\Delta T] }
\end{aligned}
$$

Here, the coefficient $c_{\dot{\delta}}$ represents a relatively fast first-order dynamic which indicates that, following an initial input, $\dot{\delta}_{\mathrm{d}}$ will reduce to zero. A second coefficient, $c_{r}$, is also included to provide a link between $\ddot{\delta}_{\mathrm{d}}$ and the control input, without which 
the LQR gain generated for $\dot{\delta}_{\mathrm{d}}$ would be zero. This effectively models an aspect of expected driver behaviour in that the presence of yaw rate will produce a reduction in the rate of change in steering angle. Since $c_{r}$ is small, the coupling is relatively weak, but informal testing showed that the overall closed-loop performance is undoubtedly improved.

Note that equation (18) is used only for the generation of the LQR gain matrix. During operation, the reference model reverts to the form of equation (15), and thus this representation of driver behaviour is removed and replaced by the known steering input and its time derivative.

\subsubsection{Cost function design}

The primary feedback is designed using a quadratic cost function which attempts to create a neutral steer characteristic by utilizing the definition of steady state yaw rate gain

$$
\frac{r}{\delta_{\mathrm{d}}}=\frac{U}{l+\left(K U^{2}\right) / g}
$$

For neutral steer, the understeer coefficient $K$ is zero and the following condition must be satisfied

$$
r=\frac{U}{l} \delta_{\mathrm{d}}
$$

Accordingly, the neutral steer cost is defined as

$$
J=\int\left(r-\frac{U}{l} \delta_{\mathrm{d}}\right)^{2} \mathrm{~d} t+\int\left(\frac{1}{u_{m}^{2}}\right) u^{2} \mathrm{~d} t
$$

The second term costs the control action via an 'input scaling', $u_{m}$, the value of which is tuned to allow the controller to request the maximum yaw moment that can be generated by the differential without saturating the tyres.

The choice of cost function is clearly dependent upon the characteristics that are desired in the controlled vehicle and it is likely that other equally appropriate functions could have been chosen here. However, the aim of this paper is not to specify how the 'ideal' vehicle should behave but, rather, how it can be made to behave through the use of a controlled differential. The two cost functions chosen here should provide ample scope for this to be achieved.

\subsection{Secondary feedback}

The purpose of the secondary controller is to minimize the deviation in yaw behaviour between the reference and vehicle models. Errors will occur owing to the extra complexity in the vehicle model (for example, additional degrees of freedom) and, more significantly, owing to the fact that the vehicle model is non-linear. Application of linear optimal control theory requires models to be represented in (linear) state-space form. Therefore, in order to allow the secondary feedback also to be designed using LQR, Matlab's 'linmod' function is employed to linearize the non-linear vehicle model. The combined reference and vehicle model can thus be represented as a single linear system with the secondary feedback torque transfer as its input (Fig. 3). Linearizing this system yields its state-space representation, which can then be used to design the secondary feedback controller.

Since the objective of the secondary feedback is to minimize the error between the yaw rates of the reference and vehicle models, the following cost function is employed

$$
J=\int\left(r_{\mathrm{r}}-r_{\mathrm{v}}\right)^{2} \mathrm{~d} t+\int\left(\frac{1}{u_{m}^{2}}\right) u^{2} \mathrm{~d} t
$$

where the subscripts ' $r$ ' and ' $v$ ' represent the reference and vehicle models respectively. An input scaling, $u_{m}$, was chosen in the same way as described for the primary feedback.

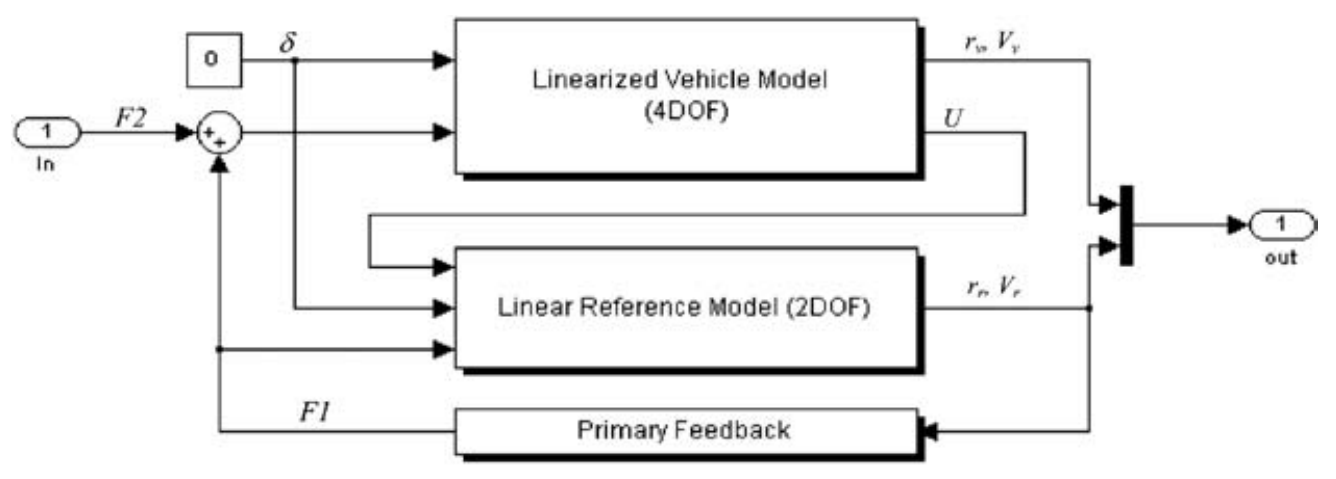

Fig. 3 Combined linear system 


\subsection{Implementation}

\subsubsection{Controlled differential}

Upon receiving a torque transfer demand from the yaw moment controller, it is necessary to engage the appropriate clutch to allow the differential to transfer the desired level of torque. A series of simple logical rules can be used to achieve this. However, it is firstly necessary to define the sliding speed of the two clutches

$$
\begin{aligned}
& \omega_{\mathrm{sr}}=\omega_{\mathrm{cr}}-\omega_{\mathrm{r}} \\
& \omega_{\mathrm{sl}}=\omega_{\mathrm{r}}-\omega_{\mathrm{cl}}
\end{aligned}
$$

The sign of the sliding speed is significant in deciding whether or not it is possible to transfer torque in a particular direction. For example, if (negative) torque transfer to the right-hand wheel is required, then the right-hand clutch should be engaged, provided that $T_{\text {cr }}$ is positive. However, $T_{\text {cr }}$ will only be positive if shaft A (Fig. 1) is travelling faster than the righthand driveshaft and hence if $\omega_{\text {sr }}$ is also positive. If it is not, then engaging the right-hand clutch will only serve to reduce the speed of the right-hand wheel (and thus reduce the torque flowing to it), and so the clutch should be disengaged. Similarly, when attempting to transfer torque to the left-hand wheel, shaft B must be travelling slower than the right-hand driveshaft and hence $\omega_{\text {sl }}$ must be positive. The rules for clutch selection are thus as shown in Table 1 .

Note that, when torque transfer to the slower wheel is being attempted, the sliding speed will always be in the required direction. However, when attempting to transfer torque to the faster wheel, this will depend on the gear ratios employed.

\subsubsection{Active brake control}

Precisely the same yaw moment controller is used for ABC. Although the output from this controller is torque transfer, this is equivalent to demanding a yaw moment which can be obtained from

$$
N_{\mathrm{d}}=\Delta T \frac{t}{r_{\mathrm{r}}}
$$

Table 1 Overdriven differential operation

\begin{tabular}{lccl}
\hline $\begin{array}{l}\text { Torque transfer } \\
\text { demand }\end{array}$ & $\omega_{\mathrm{sr}}$ & $\omega_{\mathrm{sl}}$ & Action \\
\hline+ & NA & + & Engage left-hand clutch \\
+ & NA & - & Disengage both clutches \\
- & + & NA & Engage right-hand clutch \\
- & - & NA & Disengage both clutches \\
\hline
\end{tabular}

Having obtained a desired yaw moment, it is necessary to decide how the brakes should be applied to generate it. Single-wheel braking only is used here, and four simple rules are used to determine which brake is chosen. It is clear from Fig. 4 that, if the desired yaw moment is positive, one of the right-hand brakes should be employed, whereas, if it is negative, one of the left-hand brakes should be employed. Whether that brake is at the front or the rear is determined via analysis of the vehicle yaw rate. From the definition of the neutral steer cost in section 3.2.3, the condition for neutrality was given as

$$
r_{\mathrm{n}}=\frac{U}{l} \delta
$$

Hence, if $|r|>\left|r_{\mathrm{n}}\right|$, the vehicle may be assumed to be oversteering and so the rear slip angles may be assumed to be larger than the front slip angles. Since the front tyres will therefore typically have more longitudinal force capacity (depending on the vertical load, which is not considered here), the front brakes are used. Similarly, if $|r|<\left|r_{\mathrm{n}}\right|$, the vehicle may be assumed to be understeering and the rear brakes are used. These four rules can be combined to give the brake selection logic shown in Table 2. The one exception to the logic shown in the table is when the driver is applying opposite lock (identified as when the steering angle and yaw rate are in different directions). Using the logic above, opposite lock could be interpreted as understeer, and so an additional

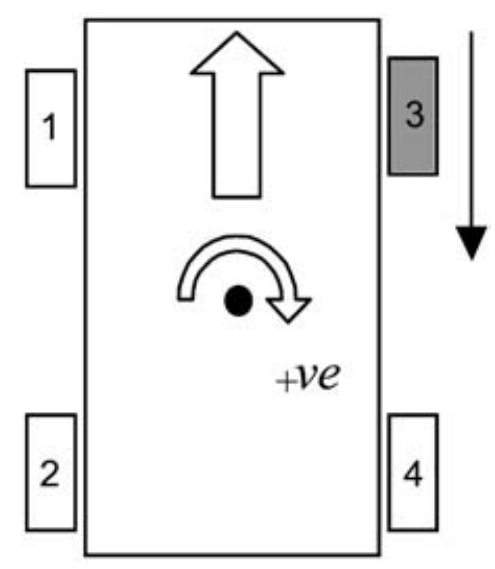

Fig. 4 Application of a positive yaw moment via the right front brake

Table 2 Brake selection logic

\begin{tabular}{lll}
\hline & $N_{\mathrm{d}}<0$ & $N_{\mathrm{d}}>0$ \\
\hline$|r|>\left|r_{\mathrm{n}}\right|$ & 1 & 3 \\
$|r|<\left|r_{\mathrm{n}}\right|$ & 2 & 4 \\
\hline
\end{tabular}


rule states that, if such a condition is detected, only one of the front wheels may be chosen.

The braking torque that should be applied to the chosen wheel is calculated assuming there is sufficient coefficient of friction at the road/tyre interface, thus allowing the braking force generated at a single tyre to be written as

$$
F_{\mathrm{b}}=\frac{T_{\mathrm{b}}}{r_{\mathrm{r}}}
$$

The yaw moment generated by this braking force may be written as

$$
N=\frac{t}{2} F_{\mathrm{b}}
$$

Hence, the braking torque required at the chosen wheel is given by

$$
T_{\mathrm{b}}=\frac{2 N_{\mathrm{d}} r_{\mathrm{r}}}{t}
$$

\section{PERFORMANCE EVALUATION}

An active differential and an $A B C$ system both attempt to create a desired yaw moment in an almost

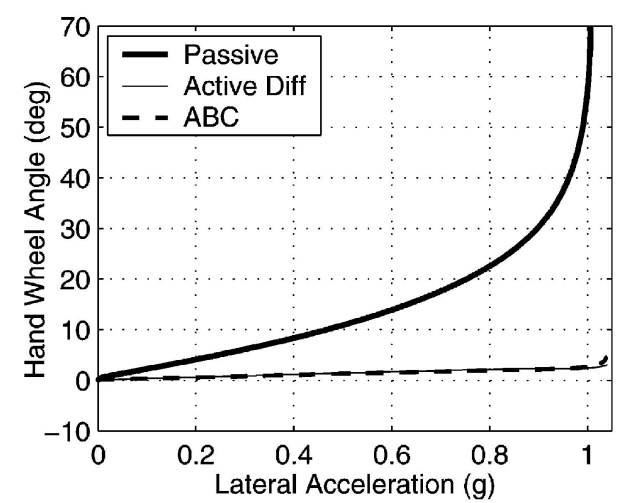

(a)

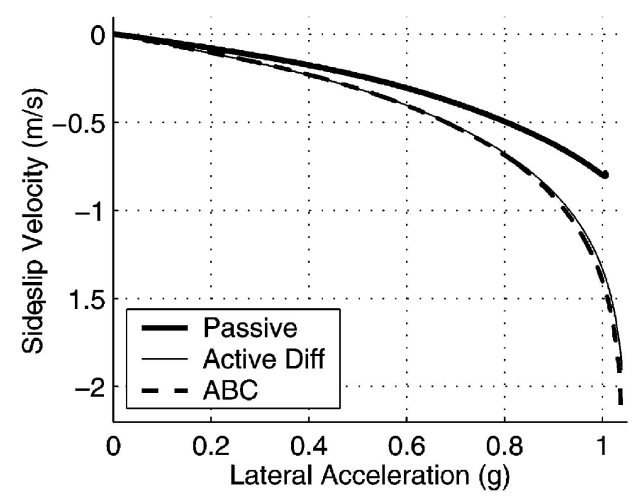

(c) identical manner-by creating different longitudinal forces on each side of the vehicle. However, the differential achieves this by increasing the longitudinal force on one side and reducing it on the other, while the $\mathrm{ABC}$ system simply reduces the longitudinal force on one side of the vehicle. The ABC system also has the option of using the front tyres to produce a required yaw moment while the differential is restricted to using the rear tyres only. As a result of these differences (and the non-linear nature of the tyres), the performance of the two systems is not always identical, as will be illustrated via analysis of four different manoeuvres in the following sections.

\subsection{Understeer coefficient manoeuvre}

Here the speed of the vehicle is held at $20 \mathrm{~m} / \mathrm{s}$ while the steering wheel angle is increased at $2 \mathrm{deg} / \mathrm{s}$ $(0.035 \mathrm{rad} / \mathrm{s})$ until the limit of the vehicle is reached. The understeer coefficient is then obtained by subtracting the neutral steer hand wheel angle from the actual hand wheel angle. Since the passive vehicle understeers (Fig. 5a), the applied yaw moment must be in the direction in which the vehicle is turning. The active differential achieves this by transferring

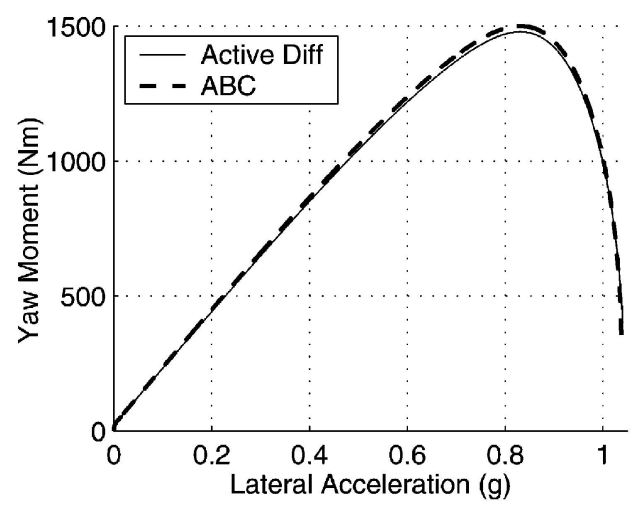

(b)

Fig. 5 Comparison of actuators during a $20 \mathrm{~m} / \mathrm{s}$ constant speed understeer coefficient test 
torque to the outside rear wheel, while the $A B C$ system applies a braking torque to the inside rear wheel. In spite of the inside wheel being more lightly loaded, it can be seen from Fig. 5b that the ABC system is able to generate an almost identical yaw moment to the active differential and therefore an almost identical reduction in understeer coefficient (Fig. 5a). It should also be noted from Fig. $5 c$ that, with both systems, this improvement in neutral steer characteristics comes at the expense of increased sideslip velocity and therefore sideslip angle.

\subsection{Braking in a turn manoeuvre}

In scenarios where yaw stability is compromised, it is crucial to be able rapidly to generate understeer by applying a yaw moment that opposes the direction in which the vehicle is turning. It may be anticipated that the $\mathrm{ABC}$ controller would have an advantage over the active differential in such circumstances because it uses the heavily loaded outside wheel to generate understeer. However, a closed-loop brakingin-a-turn manoeuvre demonstrates that this will not always be the case. During this manoeuvre the vehicle is driven at a constant speed of $40 \mathrm{~m} / \mathrm{s}$ into a $185 \mathrm{~m}$ radius corner, yielding a lateral acceleration of ca $0.9 \mathrm{~g}$. After $10 \mathrm{~s}$ (when the vehicle has settled into a steady state cornering condition) a constant braking torque is applied to the wheels, yielding a deceleration of approximately $0.5 \mathrm{~g}$.

As can be seen from Fig. 6b, up to the point where the brakes are applied, the two actuators apply an almost identical yaw moment as they attempt to reproduce neutral steer characteristics. Once the brakes are applied, the vehicle begins to oversteer and the active differential therefore rapidly switches the direction of torque transfer to the inside wheel. The understeer generated is sufficient to reduce the steering correction required from the driver by 97 per cent. In spite of its expected superiority (see above), the $A B C$ system does not quite achieve the same improvement in stability and the driver has to apply around double the steering correction to compensate for the oversteer experienced when the brakes are applied (Fig. 6a). This is due to the fact that, prior to brake application, the $\mathrm{ABC}$ is applying braking torque to the inside rear wheel to reduce understeer. Unfortunately, when the brakes are applied, this immediately becomes the worst possible course of action since it is excessive (braking) slip on the inside rear wheel that is associated with the instability experienced by the passive system. The yaw moment controller takes around $0.1 \mathrm{~s}$ to react to the oversteer that ensues from the brake application, and so during this time the $\mathrm{ABC}$ is only serving to degrade stability further by braking the 'wrong' wheel. It is, of course, also true that during the same period the active differential is transferring torque in the wrong direction. However, this appears to be less of a problem, because, although this still leads to additional braking torque being applied to the inside rear wheel, it is only approximately half the amount applied by the $\mathrm{ABC}$ (the other half being applied as positive torque to the outside wheel).

It should also be noted that for this test it was necessary to reduce the secondary feedback input scaling by 50 per cent for the $\mathrm{ABC}$ in order to prevent it from locking one of the wheels after the brakes had been applied (note that in reality, anti-lock braking system (ABS) functionality would be included in the controller, making it unnecessary to retune the input

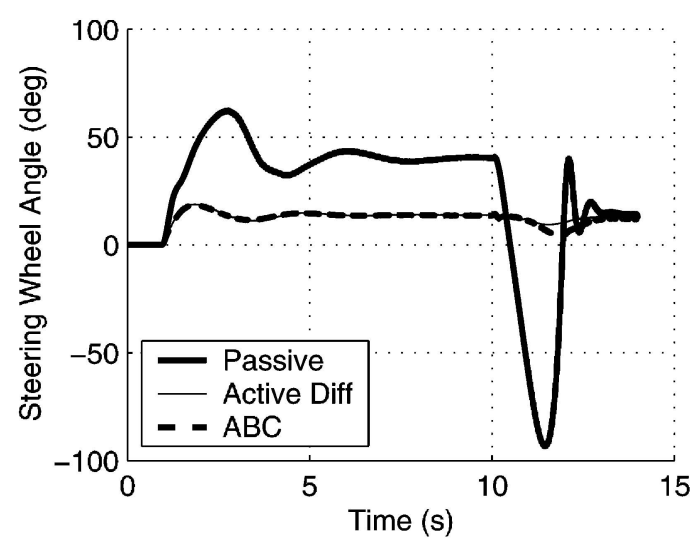

(a)

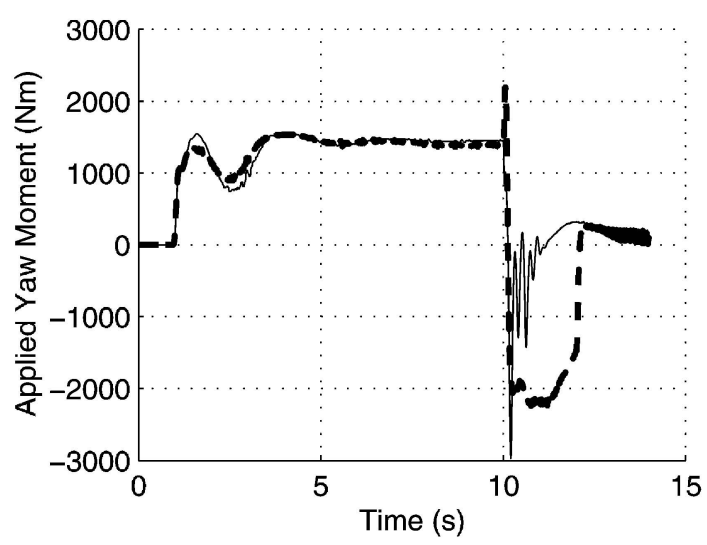

(b)

Fig. 6 Comparison of actuators for a closed-loop braking in a turn test from $40 \mathrm{~m} / \mathrm{s}$ on a constant $185 \mathrm{~m}$ radius-vehicle turns into the corner at $1 \mathrm{~s}$ and the brakes are applied at $10 \mathrm{~s}$ 
scaling). This highlights a further disadvantage of the ABC. When the driver is applying the brakes, it reduces the scope for the $A B C$ to generate a yaw moment, since the amount of additional braking torque that can then be applied before saturation occurs obviously decreases. As indicated above, this problem is compounded by the fact that the $\mathrm{ABC}$ attempts to generate all of the required yaw moment through one wheel. By contrast, the active differential spreads the torque it applies across two wheels, and so it is generally less likely to spin/lock one of its wheels. This perhaps suggests that the ABC controller would be improved by allowing application of two brakes where possible.

\subsection{Lane change}

The manoeuvres described above were all carried out at constant speed, the throttle being modulated to compensate for any loss in speed owing to cornering or control action. Without this constraint, the fact that the application of ABC will reduce vehicle speed may be an advantage when the vehicle is at the limit. However, this is not necessarily the case, as can be demonstrated with a closed-loop lane change manoeuvre (Fig. 7). Here, the steering of the vehicle is controlled to follow a lane change trajectory, defined by twice integrating a sinusoidal lateral acceleration profile. At $40 \mathrm{~m} / \mathrm{s}$ the manoeuvre should yield a peak lateral acceleration of $0.9 g$. However, in an attempt to push the vehicle closer to the limit, an initial speed of $50 \mathrm{~m} / \mathrm{s}$ is set and then allowed to fall freely as the vehicle goes through the manoeuvre (Fig. 7c). This results in a peak lateral acceleration of just over $1.0 \mathrm{~g}$ (Fig. $7 \mathrm{~d}$ ).

As can be seen from Fig. 7c, the $A B C$ system does reduce the vehicle speed more than the active differential (by an additional $0.8 \mathrm{~m} / \mathrm{s}$ ). In spite of this, the performance of the $\mathrm{ABC}$ controller is significantly inferior to the active differential. This is illustrated in Figs $7 \mathrm{e}$ and $\mathrm{f}$ where it may be seen that the active differential succeeds in generating a near neutral steer yaw rate while the peak yaw rate for the $A B C$ controller is only just over half that required for an ideal neutral steer response. This results in a higher driver workload for the ABC vehicle (Fig. 7a).

The principal reason that the $\mathrm{ABC}$ controller is less effective here again appears to be related to its use of a single wheel to generate the required yaw moment. This problem is magnified on a manoeuvre such as this where it is the more lightly loaded inside wheels that are braked (to reduce understeer). Again, since the controller does not include ABS functionality, the input scaling on both the primary and secondary feedbacks had to be reduced to prevent wheel locking. The applied yaw moment thus peaks at around 50 per cent of that applied by the active differential (Fig. 7b). It would therefore appear that, in this case, any advantage accruing from the vehicle being slowed down is cancelled out by the lower yaw moment capacity of the ABC system at high lateral accelerations (in cases where the inside wheels are being employed). It is also worth noting that, except where the handling limit of the vehicle is exceeded, slowing the vehicle down is not always regarded as a desirable effect.

\section{ENERGY CONSIDERATIONS}

Having illustrated the differences between the two actuation systems in terms of vehicle dynamic performance, this section will focus on their relative efficiency by analysing the energy balance of the vehicle. The energy sources and sinks present in the vehicle model can be broken down into a number of components, each of which are detailed in Table 3.

Additionally, mechanical energy may be stored (and released) via the kinetic energy of the wheels and body. It should be noted that the kinetic and heat energy dissipated should be equal to the energy input, and this was accurately validated in the simulation.

Using the expressions in Table 3, the energy balance for the three manoeuvres from the previous section have each been analysed. The results are described below.

Table 3 Energy sources and sinks for the 4DOF vehicle model. Note that the vehicle is assumed to roll about its $x$ axis

\begin{tabular}{lc}
\hline Sources & Calculation $(\mathrm{J})$ \\
\hline & Kinetic \\
Powertrain & $\int T_{\mathrm{i}} \omega_{\mathrm{c}} \mathrm{d} t$ \\
& Heat \\
Tyre longitudinal slip & $\sum_{n=1}^{4} \int F_{x_{n}}\left(r_{\mathrm{r}} \omega_{n}-U_{\mathrm{t}_{n}}\right) \mathrm{d} t$ \\
Tyre lateral slip & $\sum_{n=1}^{4} \int F_{y_{n}} V_{\mathrm{t}_{n}} \mathrm{~d} t$ \\
Brakes & $\sum_{n=1}^{4} \int T_{\mathrm{b}_{n}} \omega_{n} \mathrm{~d} t$ \\
Differential & $\int^{4} 2 \Delta T_{\mathrm{cl}} \omega_{\mathrm{sl}} \mathrm{d} t+\int 2 \Delta T_{\mathrm{cr}} \omega_{\mathrm{sr}} \mathrm{d} t$ \\
\hline
\end{tabular}




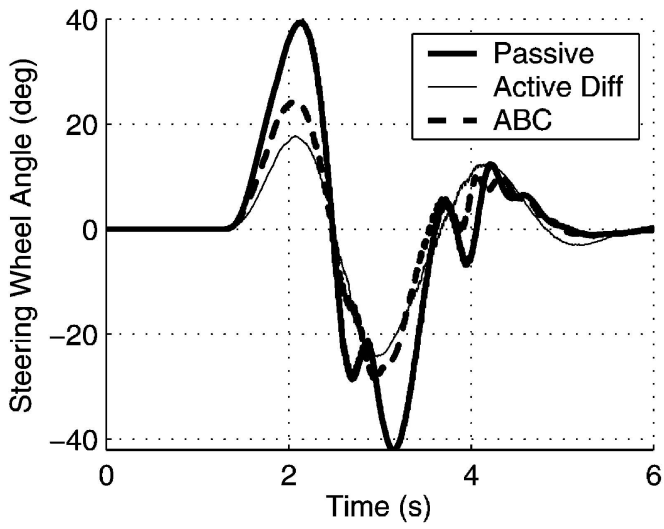

(a)

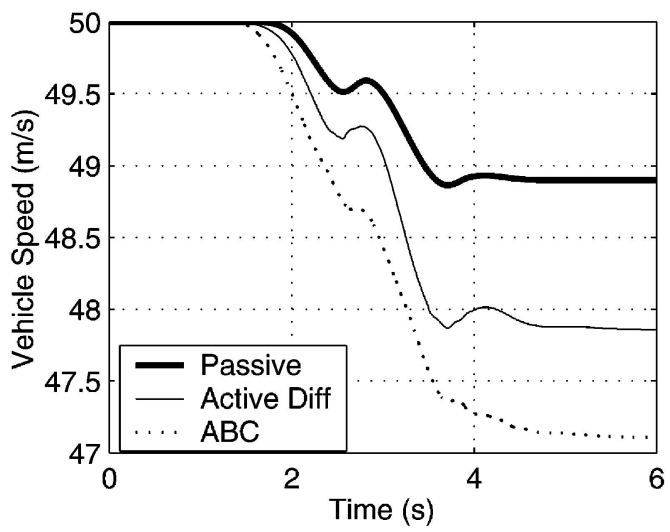

(c)

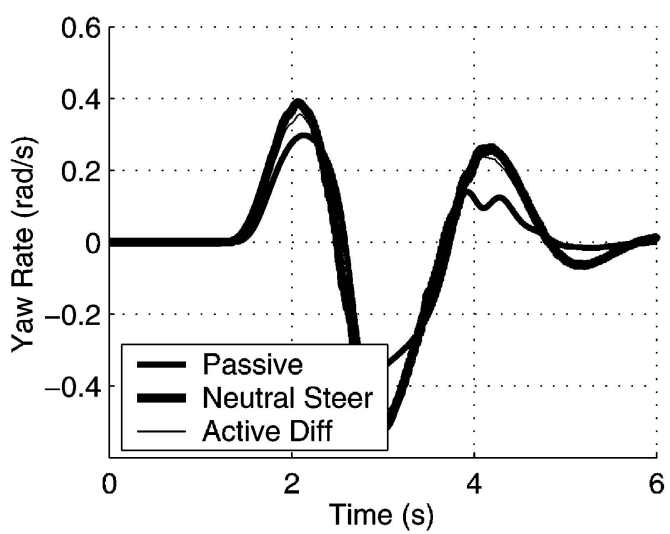

(e)

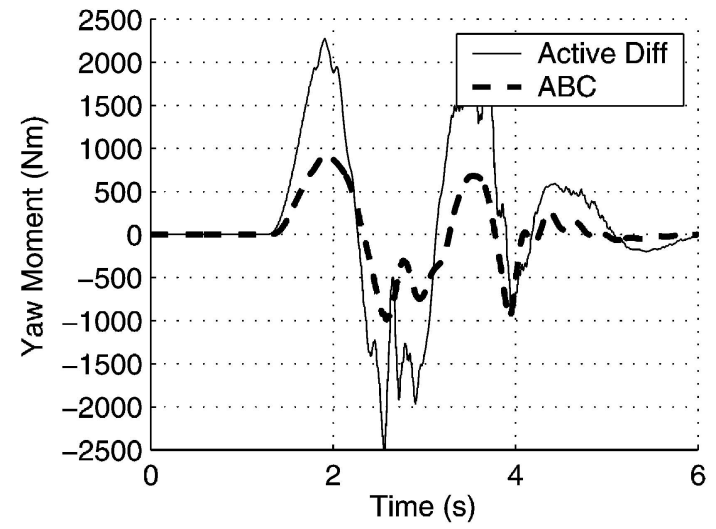

(b)

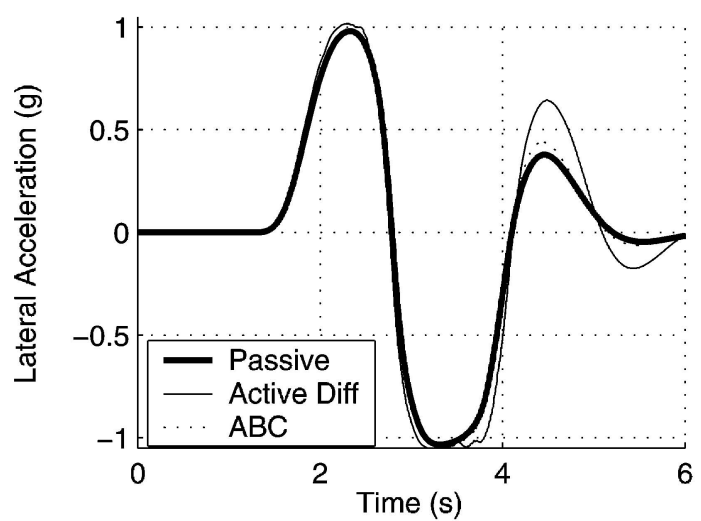

(d)

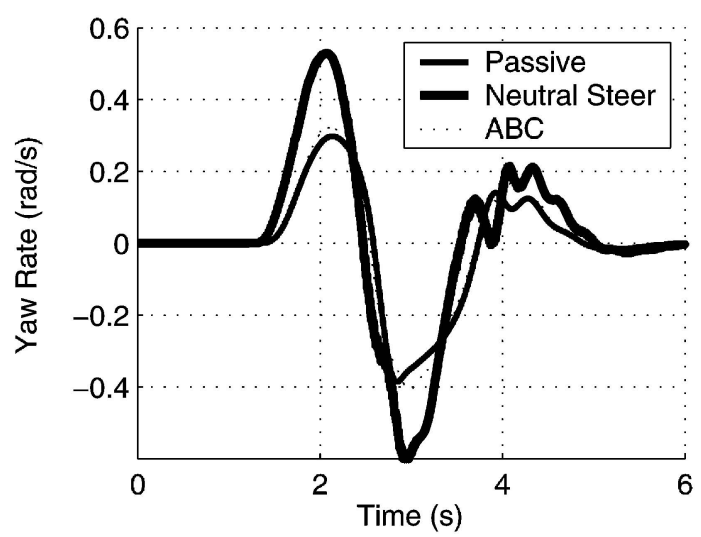

(f)

Fig. 7 Comparison of actuators during a closed-loop lane change manoeuvre commenced at $50 \mathrm{~m} / \mathrm{s}$

\subsection{Understeer coefficient manoeuvre}

The energy account for the understeer coefficient manoeuvre described in section 4.1 is shown in Fig. 8. Note that the energy allocated to the vehicle and wheels in Fig. 8a represents the final kinetic energy of the vehicle. Since the initial kinetic energy is zero for this test, the sum of the bars in Fig. $8 \mathrm{a}$ is equal to the energy input shown in Fig. $8 \mathrm{~b}$.
As can be seen from Fig. $8 b$, the energy required for the $A B C$ vehicle to complete the manoeuvre is over twice that consumed by the passive and active differential vehicles (Fig. 8b). It turns out that, in order to produce the same improvement in neutral steer, around 9 times more energy is dissipated in the brakes than in the clutches of the differential (Fig. 8a). It should also be noted that, by transferring torque to the more heavily loaded outside wheel, the 


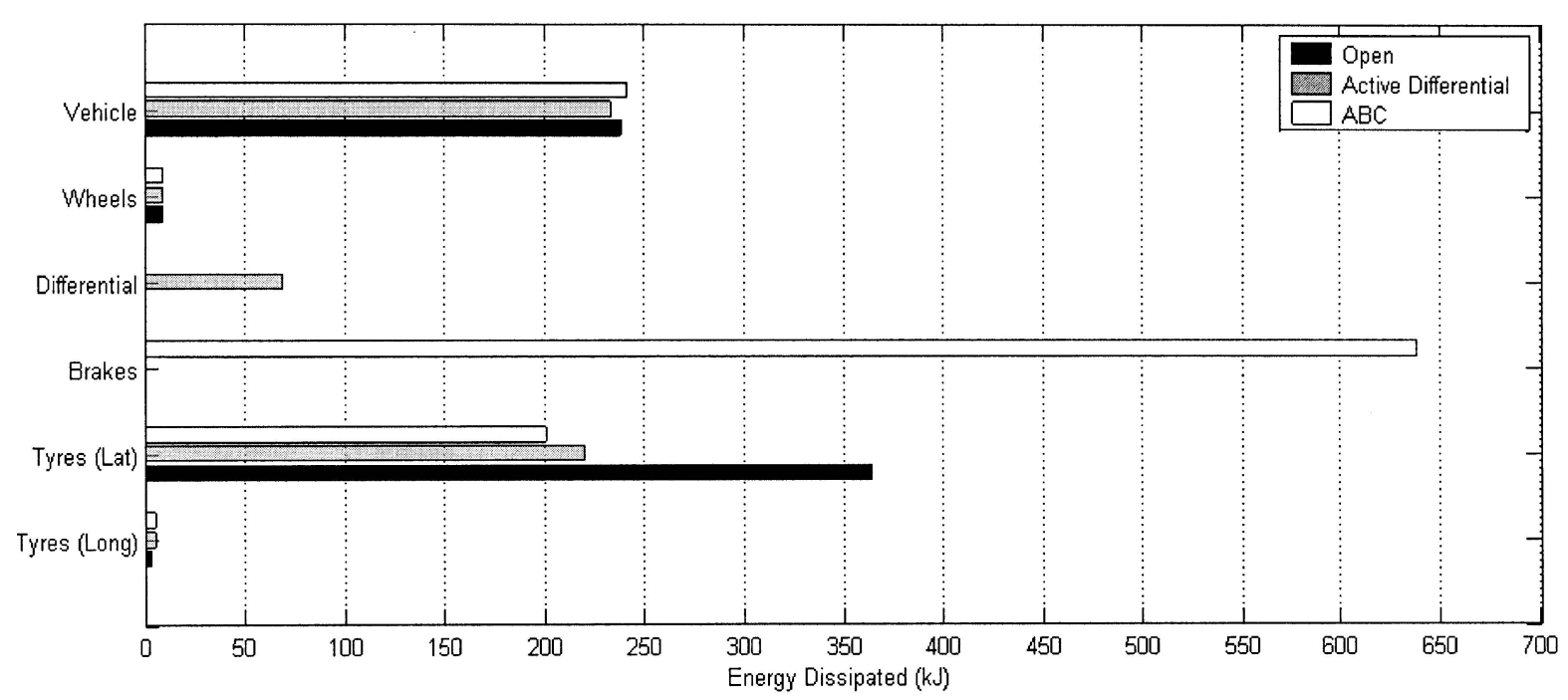

a)

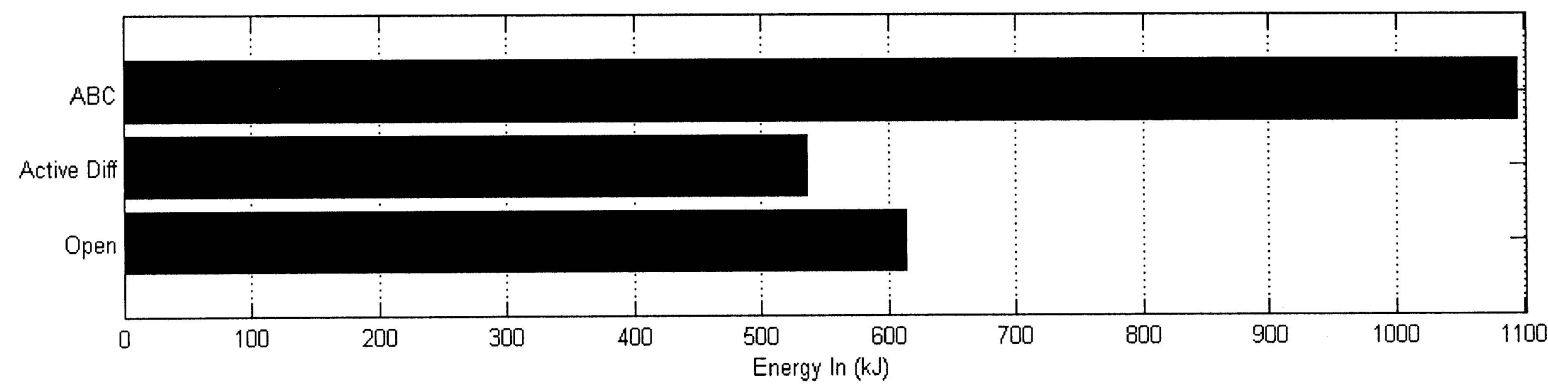

b)

Fig. 8 Energy account for a constant speed $(20 \mathrm{~m} / \mathrm{s})$ understeer coefficient test

overdriven differential actually reduces the amount of energy required to complete this manoeuvre (compared with the passive vehicle) by making more efficient use of the tyres (Fig. 8a).

\subsection{Braking in a turn manoeuvre}

The relative inefficiency of the $\mathrm{ABC}$ system is also demonstrated in the energy account for the brakingin-a-turn manoeuvre of section 4.2 (Fig. 9). As before, the energy allocated to the vehicle and wheels in Fig. 9a represents the final kinetic energy of the vehicle, and, since the initial kinetic energy is again zero, the sum of the bars in Fig. $8 \mathrm{a}$ is equal to the energy input shown in Fig. 8b.

From Fig. 9 it may be seen again that the additional energy dissipated in the brakes (as a result of $\mathrm{ABC}$ ) is over 9 times that dissipated in the differential (Fig. 9a), and the $A B C$ vehicle needs almost 50 per cent more energy than the passive vehicle to complete the manoeuvre (compared with 6 per cent more with the active differential, Fig. 9b). Again some of the additional energy consumed by the differential is offset by more efficient use of the tyres (this appears to be due to torque transfer to the more heavily loaded wheel in the first phase of the manoeuvre).

\subsection{Lane change}

In the lane change manoeuvre of section 4.3 , a speed controller was not employed and additional energy was therefore not supplied to the vehicle once the manoeuvre had commenced. Figure 10 shows the energy dissipated from when the manoeuvre commenced at a speed of $50 \mathrm{~m} / \mathrm{s}$. It can be seen from the chart that, without the need to counteract the additional driving torque being supplied to the wheels (to maintain a constant speed), the relative energy loss in the brakes is lower here than for the previous two manoeuvres. However, in another illustration of its greater efficiency, the energy loss in the differential is still only 25 per cent of that lost in the brakes, in spite of the fact that it is applying a peak yaw moment that is more than double that applied by the ABC system (see Fig. 7a, section 4.3). 


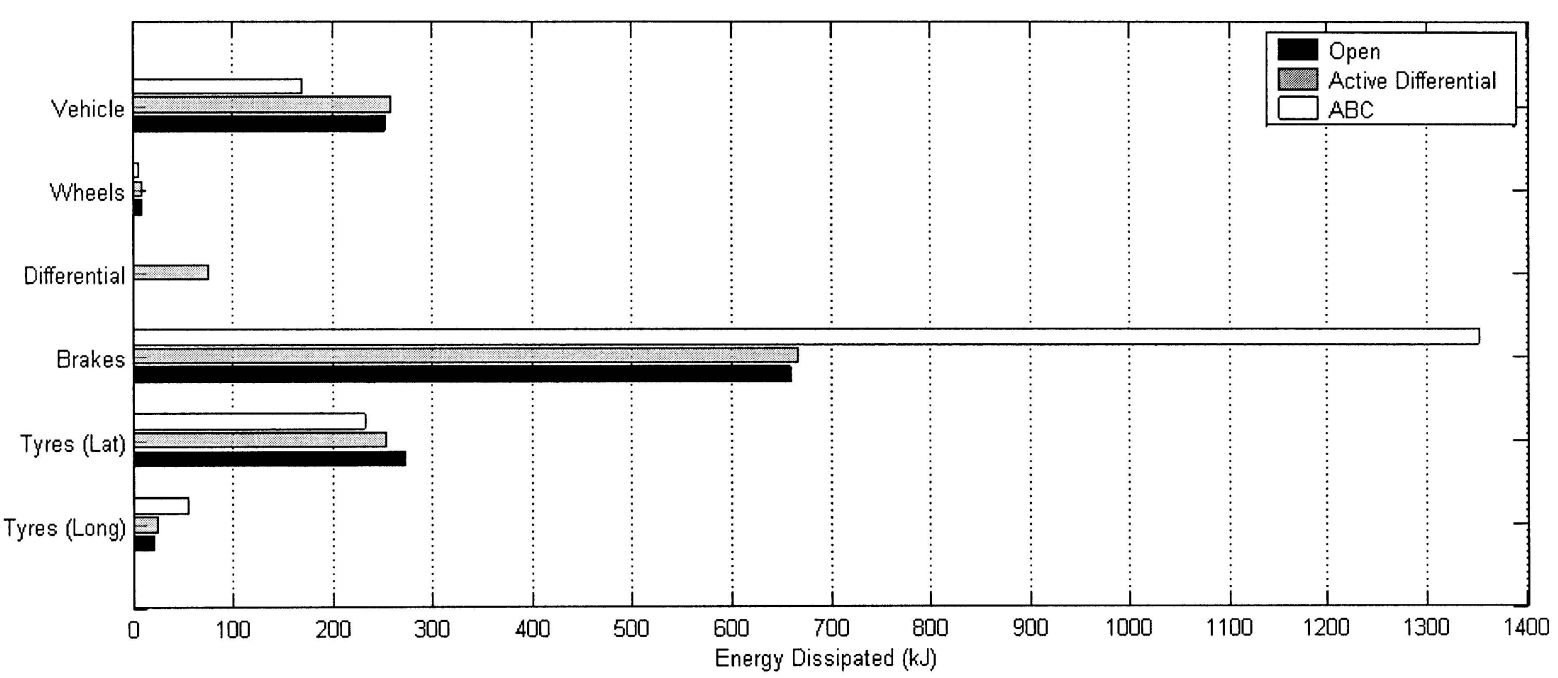

a)

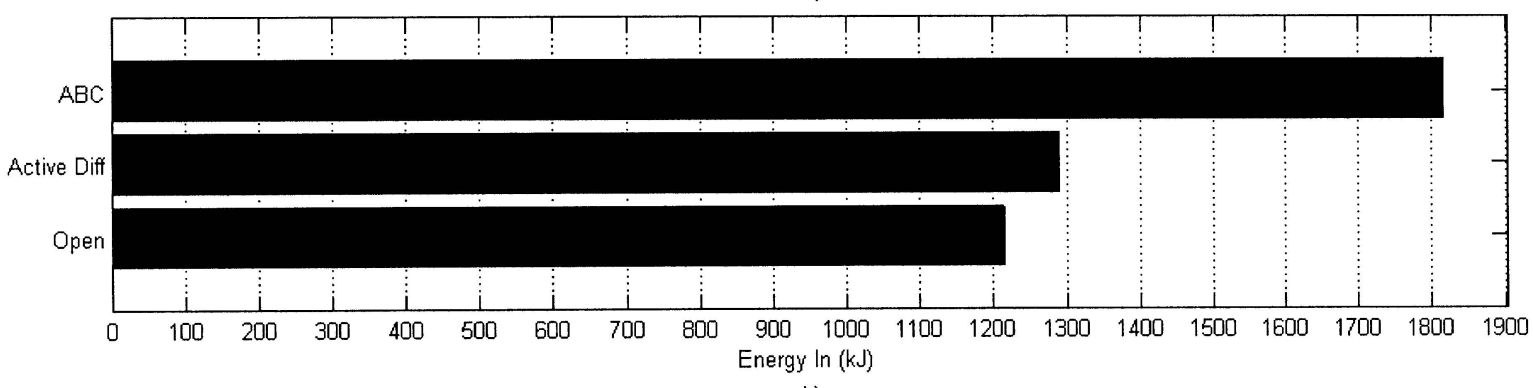

b)

Fig. 9 Energy account for a $40 \mathrm{~m} / \mathrm{s} 0.9 \mathrm{~g}$ braking-in-a-turn manoeuvre

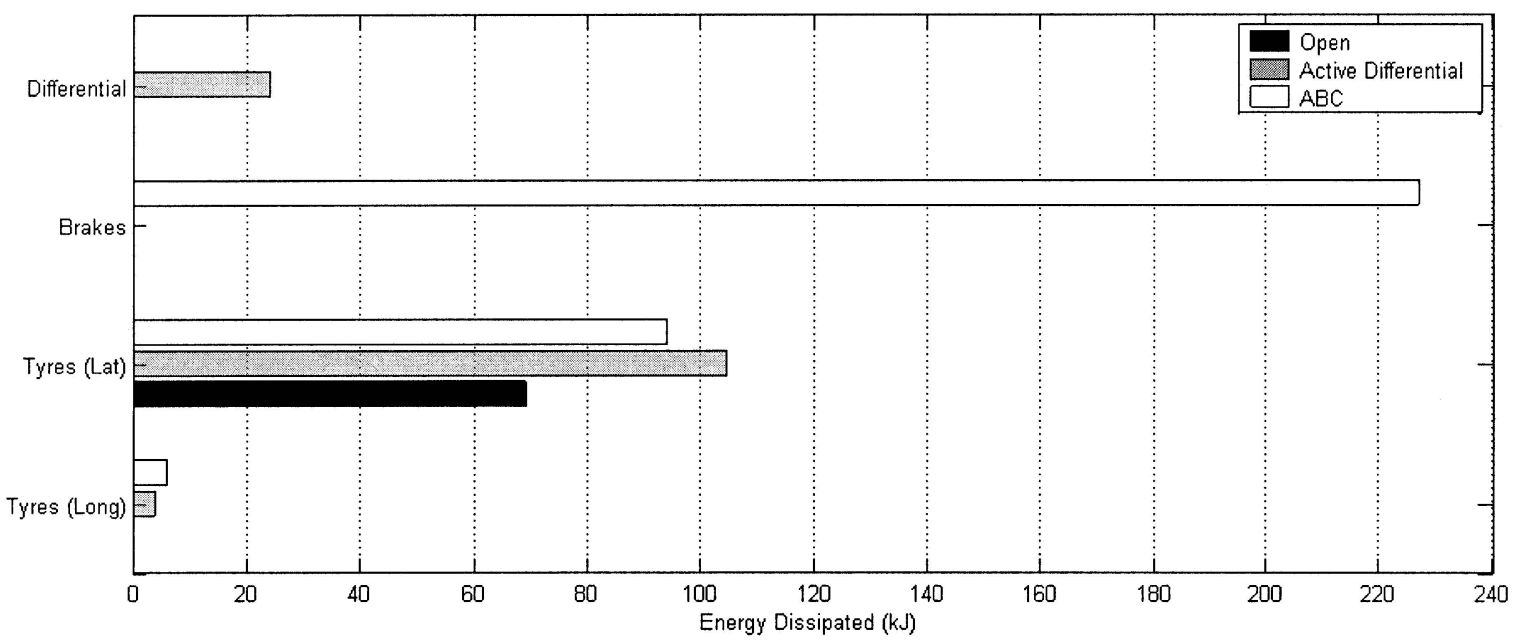

Fig. 10 Energy account for a closed-loop lane change manoeuvre commenced at $50 \mathrm{~m} / \mathrm{s}$

\section{CONCLUSIONS}

The development of a yaw moment controller using linear optimal control theory allowed the comparison of an overdriven differential with an active brake control $(\mathrm{ABC})$ system implemented with precisely the same control structure. It has been shown that the two systems produce a similar vehicle dynamic performance, although the active differential appears to possess some distinct advantages. These arise principally because the active differential creates the demanded yaw moment using two wheels instead of 
one, thus making it less prone to saturating the tyres and therefore giving it greater yaw moment capacity in some scenarios. This greater capacity appears to compensate for any advantage the ABC system may have in reducing vehicle speed in stability-critical situations. It is not therefore evident that there would be any value in integrating the two systems. However, the wheel selection strategy employed for the ABC system here was relatively simple and it is possible that its performance could be improved in some scenarios if it were allowed to use more than a single brake. It is conceivable that such an improved system could still be of considerable value in stability-critical situations, since, unlike the active differential, it naturally slows the vehicle down. It is nevertheless clear that yaw moment control via the active differential has the potential to be at least a match for brake intervention in many scenarios.

The benefits of active torque transfer control over $\mathrm{ABC}$, however, are not just restricted to vehicle dynamic performance. The active differential was also shown to be considerably more efficient. This is because, instead of trying to create a lateral torque difference (and thus yaw moment) by dissipating the energy supplied to one of the wheels in the form of heat (as with the $\mathrm{ABC}$ ), the active differential simply attempts to reapportion the torque that is supplied to the wheels. The mechanism by which this is achieved - the friction clutch-still leads to some energy loss, but this is generally much lower than the energy dissipated in the brakes. Indeed, the level of energy loss observed with the ABC system (in some manoeuvres over 10 times the amount dissipated in the differential) suggests that the application of yaw moment control via brake intervention in anything other than stability-critical situations would be undesirable. By contrast, the low energy consumption of the active differential gives it the potential to apply yaw moment control throughout the operating range of the vehicle. Further work on integration of the two systems should therefore focus on the use of $A B C$ only in situations where stability has been compromised and/or it is deemed advantageous to reduce vehicle speed.

It should be noted that it is possible that the excessive energy losses in the $\mathrm{ABC}$ system may be offset to some extent by lower parasitic losses in the hydraulic actuation system and also by its relatively low weight. This is therefore also an area for further investigation. However, the results obtained here suggest that active differentials have the potential to offer a more efficient and in many cases more effective means of applying yaw moment control.

\section{ACKNOWLEDGEMENTS}

The authors would like to thank Jaguar Cars Limited and Loughborough University for supporting the publication of this paper.

\section{REFERENCES}

1 Ishikaqa, Y., Teraoka, M., Ishikawa, O., Kamibayashi, H., Izawa, T., Rohregger, W., and Yuhashi, Y. Development of hybrid l.s.d.-development of speed and torque sensing l.s.d. JSAE Autumn Convention, Japan, 10 April 1994, Proceedings 944 1994-10 (257-260), pp. 5-11.

2 Boos, M. and Koepf, P. Electronically controlled limited slip differentials and 4-wheel drive transfer gear boxes for cars. 3rd International Conference on Innovation and Reliability, Firenze, Italy, 4 August 1992, SAE paper 92A071, pp. 819-821.

3 Huchtkoetter, $\mathbf{H}$. and Klein, $\mathbf{H}$. The effect of various limited slip differentials in front wheel drive vehicles on handling and traction. SAE International Congress and Exposition, Detroit, Michigan, 26-29 February 1996, SAE paper 960717, pp. 133-134.

4 Sawase, K. Left/right drive torque adjusting apparatus for vehicle and left/right drive torque adjusting method for vehicle. US Pat. 5456641, 10 October 1995.

5 Okcuoglu, M. A descriptive analysis of gerodisc type limited slip differentials and AWD couplings. International Truck and Bus Meeting and Exposition, Winston-Salem, North Carolina, 13-15 November 1995, SAE paper 952642, pp. 16-18.

6 Teraoka, M. Development of the electro-magnetic controlled limited slip differential unit (EMCD). SAE paper 931023, 1993, pp. 253-254.

7 Ikushima, Y. and Sawase, K. A study on the effects of the active yaw moment control. SAE paper 950303, 1995, pp. 425-433.

8 Sawase, K. and Sano, Y. Application of active yaw control to vehicle dynamics by utilizing driving/ braking force. JSAE Rev., 1999, 20, 289-295.

9 Komatsu, A., Best, M., and Gordon, T. 4WS control of handling dynamics using a linear optimal reference model. In Proceedings of 5th International Symposium on Advanced Vehicle Control, AVEC 2000, Michigan, 22-24 August 2000, pp. 1-8.

10 Kwakernaak, H. and Sivan, R. Linear Optimal Control Systems, 1972, p. 193 (Wiley-Interscience, USA).

\section{APPENDIX 1}

\section{Notation}

$a_{y} \quad$ lateral acceleration $\left(\mathrm{m} / \mathrm{s}^{2}\right)$

$b \quad$ longitudinal distance from the front axle to the centre of mass (m) 


\begin{tabular}{|c|c|c|c|}
\hline$B_{\phi_{\mathrm{f}}}, B_{\phi_{\mathrm{r}}}$ & $\begin{array}{l}\text { front/rear roll damping } \\
(\mathrm{N} \mathrm{m} / \mathrm{rad} \mathrm{s})\end{array}$ & $T_{\mathrm{b}_{n}}$ & $\begin{array}{l}\text { braking torque applied to wheel } n \\
\text { (N m) }\end{array}$ \\
\hline$c$ & $\begin{array}{l}\text { longitudinal distance from the rear } \\
\text { axle to the centre of mass (m) }\end{array}$ & $T_{\mathrm{D}_{n}}$ & $\begin{array}{l}\text { total torque applied to wheel } n \\
(\mathrm{~N} \mathrm{~m})\end{array}$ \\
\hline \multirow[t]{2}{*}{$c_{r}$} & coefficient relating yaw rate to the & $T_{\mathrm{i}}$ & input torque $(\mathrm{N} \mathrm{m})$ \\
\hline & $\begin{array}{l}\text { second time derivative of the } \\
\text { steering input }\end{array}$ & $T_{1}, T_{\mathrm{r}}$ & $\begin{array}{l}\text { torque supplied to left/right wheel } \\
(\mathrm{N} \text { m) }\end{array}$ \\
\hline$c_{\dot{\delta}}$ & $\begin{array}{l}\text { coefficient relating the rate of } \\
\text { change of steering input to its time } \\
\text { derivative }\end{array}$ & $T_{\mathrm{ri}}$ & $\begin{array}{l}\text { torque in the right-hand driveshaft } \\
\text { between the differential gearing } \\
\text { and the outer clutch plate }(\mathrm{N} \mathrm{m})\end{array}$ \\
\hline$C_{\alpha \mathrm{f}}, C_{\alpha \mathrm{r}}$ & $\begin{array}{l}\text { front/rear cornering stiffness } \\
(\mathrm{N} / \mathrm{rad})\end{array}$ & $\Delta T$ & $\begin{array}{l}\text { torque transfer between the rear } \\
\text { wheels }(\mathrm{N} \mathrm{m})\end{array}$ \\
\hline$F_{1}$ & $\begin{array}{l}\text { primary feedback torque transfer } \\
(\mathrm{N} \mathrm{m})\end{array}$ & $\Delta T_{\mathrm{cl}}, \Delta T_{\mathrm{cr}}$ & $\begin{array}{l}\text { torque across the left/right-hand } \\
\text { clutch plates of an overdriven }\end{array}$ \\
\hline \multirow[t]{2}{*}{$F_{2}$} & secondary feedback torque transfer & & differential $(\mathrm{N} \mathrm{m})$ \\
\hline & $(\mathrm{N} \mathrm{m})$ & $\Delta T_{x}$ & torque transferred from the \\
\hline$F_{\mathrm{b}}$ & braking force $(\mathrm{N})$ & & differential case to the three-gang \\
\hline$F_{x}$ & total longitudinal force $(\mathrm{N})$ & & gearing $(\mathrm{N} \mathrm{m})$ \\
\hline \multirow[t]{2}{*}{$F_{x \mathrm{l}}, F_{x \mathrm{r}}$} & total left/right-hand longitudinal & $u$ & input vector \\
\hline & force $(\mathrm{N})$ & $u_{m}$ & input scaling \\
\hline$F_{x_{n}}$ & $\begin{array}{l}\text { longitudinal force generated at } \\
\text { corner } n \text { (vehicle coordinates) (N) }\end{array}$ & $U_{n}$ & $\begin{array}{l}\text { longitudinal velocity at corner } n \\
\text { (vehicle coordinates) }(\mathrm{m} / \mathrm{s})\end{array}$ \\
\hline$F_{x t_{n}}$ & $\begin{array}{l}\text { longitudinal force generated at tyre } \\
n \text { (tyre coordinates) }(\mathrm{N})\end{array}$ & $U_{\mathrm{t}_{n}}$ & $\begin{array}{l}\text { wheel centre longitudinal velocity } \\
\text { of wheel } n \text { (tyre coordinates) (m/s) }\end{array}$ \\
\hline$F_{y f}, F_{y r}$ & total front/rear lateral force $(\mathrm{N})$ & $U$ & vehicle speed $(\mathrm{m} / \mathrm{s})$ \\
\hline \multirow{2}{*}{$\begin{array}{l}I_{y f}, I_{y \mathrm{r}} \\
F_{y_{n}}\end{array}$} & lateral force generated at corner $n$ & $V$ & vehicle sideslip velocity $(\mathrm{m} / \mathrm{s})$ \\
\hline & (vehicle coordinates) $(\mathrm{N})$ & $V_{n}$ & lateral velocity at corner $n$ (vehicle \\
\hline \multirow[t]{2}{*}{$F_{y t_{n}}$} & lateral force generated at tyre $n$ & & coordinates) $(\mathrm{m} / \mathrm{s})$ \\
\hline & (tyre coordinates) $(\mathrm{N})$ & $V_{\mathrm{t}_{n}}$ & wheel centre lateral velocity of \\
\hline $\begin{array}{l}\Delta F_{z \mathrm{f}_{\text {lat }}}, \Delta F_{z \mathrm{r}_{\text {lat }}} \\
\Delta F_{z}\end{array}$ & front/rear lateral load transfer $(\mathrm{N})$ & & wheel $n$ (tyre coordinates) $(\mathrm{m} / \mathrm{s})$ \\
\hline $\begin{array}{l}\Delta F_{z_{\text {long }}} \\
F_{z}\end{array}$ & longitudinal load transfer (N) & $w$ & disturbance vector \\
\hline & $\begin{array}{l}\text { load on wheel } n(\mathrm{~N}) \\
\text { acceleration due to gravity }\left(\mathrm{m} / \mathrm{s}^{2}\right)\end{array}$ & $\begin{array}{l}W_{\mathrm{f}}, W_{\mathrm{r}} \\
\boldsymbol{X}\end{array}$ & $\begin{array}{l}\text { total front/rear axle load }(\mathrm{N}) \\
\text { state vector }\end{array}$ \\
\hline $\begin{array}{l}h_{\mathrm{f}}, h_{\mathrm{r}} \\
h_{\mathrm{g}}\end{array}$ & $\begin{array}{l}\text { front/rear roll centre height }(\mathrm{m}) \\
\text { centre of gravity height }(\mathrm{m})\end{array}$ & $Y$ & $\begin{array}{l}\text { total lateral force at the mass } \\
\text { centre }(\mathrm{N})\end{array}$ \\
\hline$h_{\mathrm{o}}^{\mathrm{s}}$ & $\begin{array}{l}\text { roll centre height at the centre of } \\
\text { gravity }(\mathrm{m})\end{array}$ & $z_{n}$ & $\begin{array}{l}\text { overdriven differential gear tooth } \\
\text { number }\end{array}$ \\
\hline$h_{1}$ & height of the centre of gravity & & \\
\hline & above the roll axis (m) & $\alpha_{\mathrm{f}}, \alpha_{\mathrm{r}}$ & average front/rear slip angle (rad) \\
\hline$I_{\mathrm{w}}$ & wheel inertia $\left(\mathrm{kg} \mathrm{m}^{2}\right)$ & $\alpha_{n}$ & slip angle of wheel $n$ (rad) \\
\hline$I_{x x}$ & roll moment of inertia $\left(\mathrm{kg} \mathrm{m}^{2}\right)$ & $\gamma_{n}$ & camber angle of wheel $n$ (rad) \\
\hline$I_{x z}$ & product of inertia $\left(\mathrm{kg} \mathrm{m}^{2}\right)$ & $\gamma_{s_{n}}$ & static camber angle of wheel $n$ (rad) \\
\hline$I_{z z}$ & yaw moment of inertia $\left(\mathrm{kg} \mathrm{m}^{2}\right)$ & $\delta_{\mathrm{d}}$ & demanded front steering input \\
\hline$J$ & LQR cost function & & (at the wheels) (rad) \\
\hline $\begin{array}{l}K_{\phi_{\mathrm{f}}}, K_{\phi_{\mathrm{r}}} \\
l\end{array}$ & $\begin{array}{l}\text { front/rear roll stiffness }(\mathrm{N} \mathrm{m} / \mathrm{rad}) \\
\text { wheelbase }(\mathrm{m})\end{array}$ & $\delta_{n}$ & $\begin{array}{l}\text { steering angle of road wheel } n \\
\text { (rad) }\end{array}$ \\
\hline$M$ & total vehicle mass $(\mathrm{kg})$ & $\varepsilon$ & inclination of the roll axis (rad) \\
\hline$N$ & yaw moment $(\mathrm{N} \mathrm{m})$ & $\eta$ & longitudinal slip \\
\hline$N_{\mathrm{d}}$ & demanded yaw moment $(\mathrm{N} \mathrm{m})$ & $\eta_{1}, \eta_{\mathrm{r}}$ & left/right rear longitudinal slip \\
\hline$p$ & roll velocity (rad/s) & $\phi$ & roll angle (rad) \\
\hline$r$ & vehicle yaw rate $(\mathrm{rad} / \mathrm{s})$ & $\omega_{\mathrm{c}}$ & differential cage speed $(\mathrm{rad} / \mathrm{s})$ \\
\hline$r_{\mathrm{n}}$ & neutral steer yaw rate $(\mathrm{rad} / \mathrm{s})$ & $\omega_{\mathrm{cl}}, \omega_{\mathrm{cr}}$ & left/right-hand inner clutch plate \\
\hline$r_{\mathrm{r}}$ & rolling radius $(\mathrm{m})$ & & speed (overdriven differential) \\
\hline$t$ & $\operatorname{track}(\mathrm{m})$ & & $(\mathrm{rad} / \mathrm{s})$ \\
\hline
\end{tabular}




\begin{abstract}
$\omega_{1}, \omega_{\mathrm{r}}$
$\omega_{\mathrm{sl}}, \omega_{\mathrm{sr}}$

left/right-hand wheel speed $(\mathrm{rad} / \mathrm{s})$ left/right-hand clutch sliding speed (overdriven differential) $(\mathrm{rad} / \mathrm{s}$ )
\end{abstract}

\section{APPENDIX 2}

This appendix describes the 4DOF model used for the development of the LQR controller. The four degrees of freedom are longitudinal, lateral, yaw, and roll motion, and the sign convention used is SAE. The structure of the model is shown in Fig. 11.

The model has four inputs: steering wheel angle (deg), driving torque $(\mathrm{N} \mathrm{m})$, torque transfer $(\mathrm{N} \mathrm{m})$, and braking torque $(\mathrm{N} \mathrm{m})$. The vehicle dynamics is calculated in the 'state-space' subsystem which is supplied with tyre forces from the 'tyre model' subsystem. The tyre model in turn is supplied with lateral and longitudinal slip from their respective subsystems. Each subsystem is described in detail in the following section.

\section{State-space subsystem}

This subsystem calculates the vehicle dynamics in state-space form. A state-space model is formed from the equations of motion for each degree of freedom. These are as follows:

Longitudinal motion

$$
M(\dot{U}+V r)=F_{x_{1}}+F_{x_{2}}+F_{x_{3}}+F_{x_{4}}
$$

Yaw motion

$$
I_{z z} \dot{r}=b F_{y_{\mathrm{f}}}-c F_{y_{\mathrm{r}}}+\frac{t}{2} F_{x_{1}}+\frac{t}{2} F_{x_{2}}-\frac{t}{2} F_{x_{3}}-\frac{t}{2} F_{x_{4}}
$$

Lateral motion

$$
M(\dot{V}+U r)=F_{y_{\mathrm{f}}}+F_{y_{\mathrm{r}}}
$$

Roll motion

$$
\begin{aligned}
\left(I_{x x}-\right. & \left.\varepsilon I_{x z}\right) p-I_{x z} \dot{r}+M h_{1} \dot{V} \\
= & -M U h_{1} r+\left(M g h_{1}-K_{\phi_{\mathrm{f}}}-K_{\phi_{\mathrm{r}}}\right) \phi \\
& +\left(-B_{\phi_{\mathrm{f}}}-B_{\phi_{\mathrm{r}}}\right) p+\left(h_{\mathrm{f}}-h_{\mathrm{o}}\right) F_{y_{\mathrm{f}}}+\left(h_{\mathrm{r}}-h_{\mathrm{o}}\right) F_{y_{\mathrm{r}}}
\end{aligned}
$$

These equations can be written in state-space form as follows

$$
\mathbf{M} \dot{\boldsymbol{X}}=\mathbf{A}^{\prime} \boldsymbol{X}+\mathbf{B}^{\prime} \boldsymbol{u}
$$

where

$$
\boldsymbol{X}=\left[\begin{array}{c}
U \\
r \\
V \\
\phi \\
p
\end{array}\right] \quad \text { and } \quad \boldsymbol{u}=\left[\begin{array}{c}
F_{x_{1}} \\
F_{x_{2}} \\
F_{x_{3}} \\
F_{x_{4}} \\
F_{y_{\mathrm{f}}} \\
F_{y_{\mathrm{r}}}
\end{array}\right]
$$

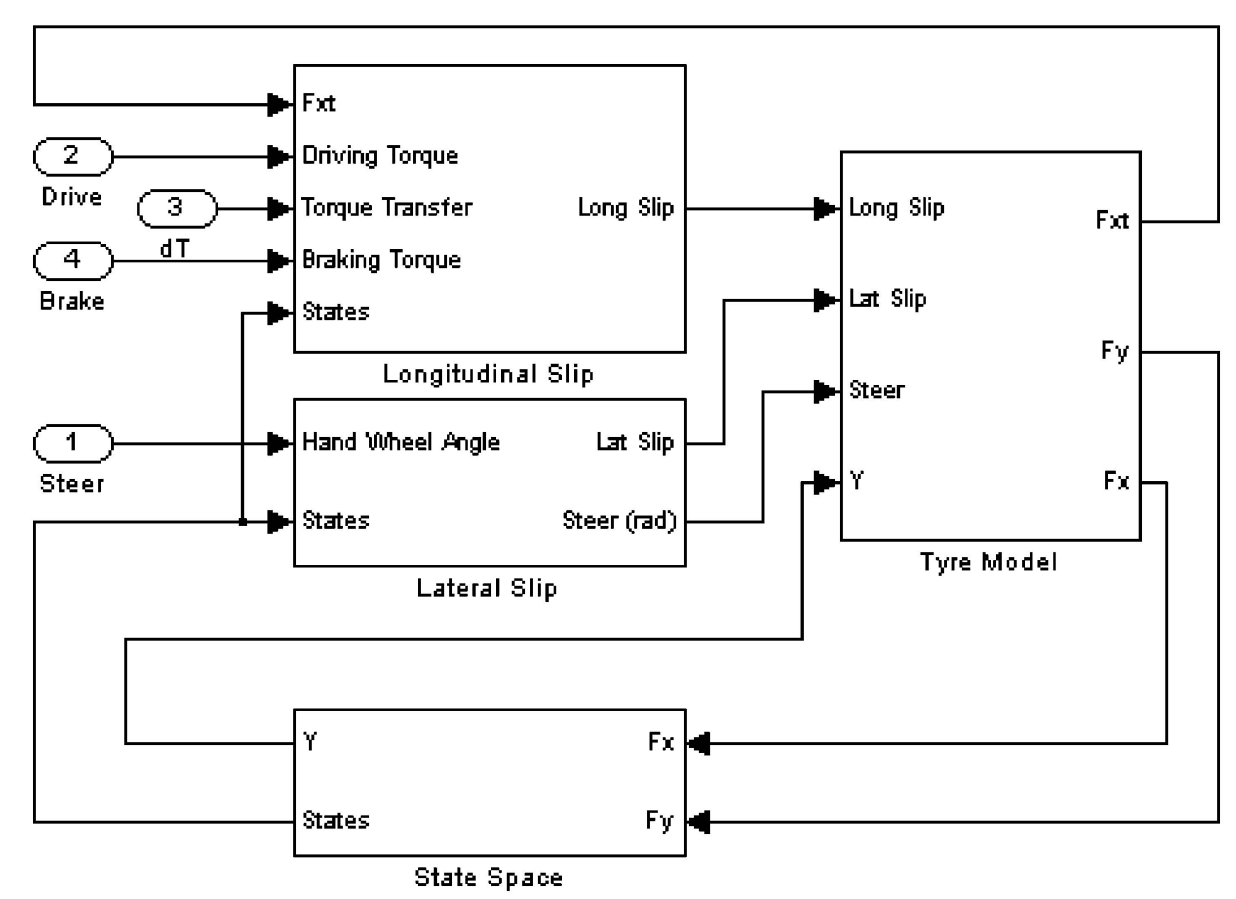

Fig. 11 Structure of the 4DOF model 
and

$$
\begin{aligned}
\mathbf{M} & =\left[\begin{array}{ccccc}
M & 0 & 0 & 0 & 0 \\
0 & 0 & M & 0 & M h_{1} \\
0 & -I_{x z} & M h_{1} & 0 & I_{x x}-\varepsilon I_{x z} \\
0 & I_{z z} & 0 & 0 & -I_{x z}+\varepsilon I_{z z} \\
0 & 0 & 0 & 0 & 0
\end{array}\right] \\
\mathbf{A}^{\prime} & =\left[\begin{array}{ccccc}
0 & M V & 0 & 0 & 0 \\
0 & -M U & 0 & 0 & 0 \\
0 & -M U h_{1} r & 0 & M g h_{1}-K_{\phi_{\mathrm{f}}}-K_{\phi_{\mathrm{r}}} & -B_{\phi_{\mathrm{f}}}-B_{\phi_{\mathrm{r}}} \\
0 & 0 & 0 & 0 & 0 \\
0 & 0 & 0 & 0 & 1
\end{array}\right]
\end{aligned}
$$

$$
\mathbf{B}=\left[\begin{array}{cccccc}
1 & 1 & 1 & 1 & 0 & 0 \\
0 & 0 & 0 & 0 & 1 & 1 \\
0 & 0 & 0 & 0 & h_{\mathrm{f}}-h_{\mathrm{o}} & h_{\mathrm{r}}-h_{\mathrm{o}} \\
\frac{t}{2} & \frac{t}{2} & -\frac{t}{2} & -\frac{t}{2} & b & -c \\
0 & 0 & 0 & 0 & 0 & 0
\end{array}\right]
$$

In addition to the state vector, the output vector $y$ is also returned by the state-space subsystem. This is calculated from

$$
\boldsymbol{y}=\mathbf{C} \boldsymbol{X}+\mathrm{D} \boldsymbol{u}
$$

where

$$
\mathbf{C}=\left[\begin{array}{ccccc}
1 & 0 & 0 & 0 & 0 \\
0 & 1 & 0 & 0 & 0 \\
0 & 0 & 1 & 0 & 0 \\
0 & 0 & 0 & 1 & 0 \\
0 & 0 & 0 & 0 & 0 \\
0 & 0 & 0 & -K_{\phi_{\mathrm{f}}} & -B_{\phi_{\mathrm{f}}} \\
0 & 0 & 0 & -K_{\phi_{\mathrm{r}}} & -B_{\phi_{\mathrm{r}}}
\end{array}\right]
$$

and

$$
\mathbf{D}=\left[\begin{array}{cccccc}
0 & 0 & 0 & 0 & 0 & 0 \\
0 & 0 & 0 & 0 & 0 & 0 \\
0 & 0 & 0 & 0 & 0 & 0 \\
0 & 0 & 0 & 0 & 0 & 0 \\
0 & 0 & 0 & 0 & \frac{1}{M} & \frac{1}{M} \\
0 & 0 & 0 & 0 & 0 & 0 \\
0 & 0 & 0 & 0 & 0 & 0
\end{array}\right]
$$

The output vector is thus

$$
\boldsymbol{y}=\left[\begin{array}{lllllll}
U & r & V & \phi & a_{y} & L_{\mathrm{f}} & L_{\mathrm{r}}
\end{array}\right]^{\mathrm{T}}
$$

\section{Longitudinal slip subsystem}

The calculation of longitudinal slip first requires calculation of wheel speed. The equation of motion for each wheel is

$$
I_{\mathrm{w}} \dot{\omega}_{n}=T_{\mathrm{D}_{n}}-F_{x_{n}} r_{\mathrm{r}}
$$

Longitudinal slip can then be calculated from

$$
\eta_{n}=\frac{r_{\mathrm{r}} \omega_{n}-U_{n}}{U_{n}}
$$

where $U_{n}$ is the forward velocity of the vehicle body at corner $n$. This is calculated from

$$
U_{n}=U+\left[\begin{array}{cccc}
\frac{t}{2} & \frac{t}{2} & -\frac{t}{2} & -\frac{t}{2}
\end{array}\right]^{\mathrm{T}} r
$$

\section{Lateral slip subsystem}

The front and rear slip angles are calculated in the lateral slip subsystem from

$$
\alpha_{n}=\delta_{n}-\frac{V_{n}}{U_{n}}
$$

where $U_{n}$ is obtained from equation (45) and

$$
V_{n}=V+\left[\begin{array}{llll}
b & -c & b & -c
\end{array}\right]^{\mathrm{T}} r
$$

Note that a non-linear function (which accounts for Ackermann) is used to convert hand wheel angle into the road wheel angles, $\delta_{n}$, which are then also adjusted for static toe and compliance steer.

\section{Tyre model subsystem}

The magic formula tyre model has four inputs. The first two, longitudinal and lateral slip, are calculated in the subsystems described in the previous two sections. The remaining two, camber and tyre load, are calculated in the tyre model subsystem.

The camber angle is calculated using static camber and roll angle. For the left-hand wheels it is therefore given by

$$
\gamma_{n}=\gamma_{\mathrm{s}_{n}}+\phi
$$

and for the right-hand wheels by

$$
\gamma_{n}=\gamma_{s_{n}}-\phi
$$


The tyre loads must take account of lateral and longitudinal load transfer. Front lateral load transfer is obtained from

$$
\Delta F_{z \mathrm{f}_{\text {lat }}}=\frac{1}{t} L_{\mathrm{f}}+\frac{h_{\mathrm{f}}}{t} F_{y_{\mathrm{f}}}
$$

and similarly lateral load transfer is obtained from

$$
\Delta F_{z \mathrm{r}_{\text {lat }}}=\frac{1}{t} L_{\mathrm{r}}+\frac{h_{\mathrm{r}}}{t} F_{y_{\mathrm{r}}}
$$

where the roll moments, $L_{\mathrm{f}}$ and $L_{\mathrm{r}}$, can be obtained from the output vector, $\boldsymbol{y}$, of the state-space subsystem [equation (42)].

The calculation used for longitudinal weight transfer is dependent on whether the vehicle is braking or accelerating. Under acceleration

$$
\Delta F_{z_{\text {long }}}=\frac{h_{\mathrm{g}}-r_{\mathrm{r}}}{2 l} F_{x}
$$

and under braking

$$
\Delta F_{z_{\text {long }}}=\frac{h_{\mathrm{g}}}{2 l} F_{x}
$$

where $F_{x}$ is the total longitudinal force applied to the vehicle. The individual tyre loads can thus be calculated as follows

$$
\begin{aligned}
& F_{z_{1}}=\frac{W_{\mathrm{f}}}{2}+\Delta F_{z \mathrm{f}_{\text {lat }}}-\Delta F_{z_{\text {long }}} \\
& F_{z_{2}}=\frac{W_{\mathrm{f}}}{2}+\Delta F_{z \mathrm{r}_{\text {lat }}}+\Delta F_{z_{\text {long }}} \\
& F_{z_{3}}=\frac{W_{\mathrm{f}}}{2}-\Delta F_{z \mathrm{f}_{\text {lat }}}-\Delta F_{z_{\text {long }}} \\
& F_{z_{4}}=\frac{W_{\mathrm{f}}}{2}-\Delta F_{z \mathrm{r}_{\text {lat }}}+\Delta F_{z_{\text {long }}}
\end{aligned}
$$

Once supplied with these four inputs, the magic formula outputs longitudinal force, lateral force, and aligning moment. For use in the state-space subsystem, these tyre forces need to be resolved into vehicle coordinates. From Fig. 12 it can be seen that the longitudinal vehicle forces will be given by

$$
F_{x_{n}}=F_{x t_{n}} \cos \delta_{n}-F_{y t_{n}} \sin \delta_{n}
$$

and, similarly, the lateral forces will be given by

$$
F_{y_{n}}=F_{x t_{n}} \sin \delta_{n}+F_{y t_{n}} \cos \delta_{n}
$$

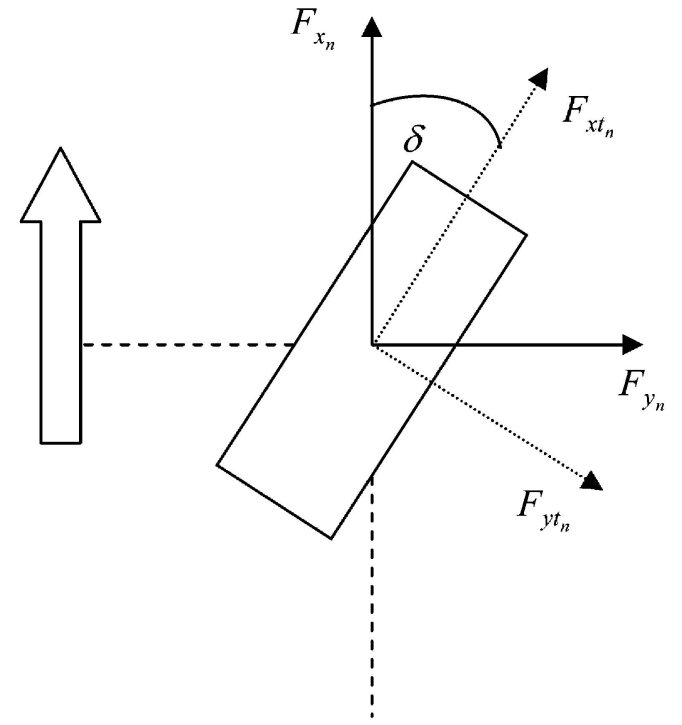

Fig. 12 Tyre coordinate transformation

Note that, on exiting the tyre model subsystem, the two front and rear lateral forces are summed to obtain the total front and rear lateral forces that are used in the state-space subsystem.

\section{APPENDIX 3}

The key drawback in terms of controllability of conventional differentials is that they will always transfer torque to the slower rotating wheel. For yaw control applications, it is desirable to have control over the direction as well as magnitude of the torque transfer. Overdriven differentials make this desirability a reality. A schematic of such a differential is shown in Fig. 1. Its operation can be illustrated by considering the governing equation of a bevel gear type differential where the left and right wheel speeds, $\omega_{1}$ and $\omega_{\mathrm{r}}$, are related to the differential cage speed, $\omega_{\mathrm{c}}$, as follows

$$
\omega_{1}+\omega_{\mathrm{r}}=2 \omega_{\mathrm{c}}
$$

The gear ratios indicated in Table 4 (see Fig. 1 for gear positions) allow the right- and left-hand inner clutch plates also to be expressed in terms of the differential cage speed

$$
\omega_{\mathrm{cr}}=\frac{z_{1} z_{5}}{z_{4} z_{2}} \omega_{\mathrm{c}}
$$

$$
\omega_{\mathrm{cl}}=\frac{z_{1} z_{6}}{z_{3} z_{4}} \omega_{\mathrm{c}}
$$


Table 4 Differential gear teeth numbers $[\mathbf{8}]$

\begin{tabular}{ll}
\hline Gear & Number of teeth \\
\hline$z_{1}, z_{2}, z_{3}$ & 42 \\
$z_{4}$ & 32 \\
$z_{5}$ & 36 \\
$z_{6}$ & 28 \\
\hline
\end{tabular}

Substituting the teeth numbers shown in Table 4 yields

$$
\begin{aligned}
& \omega_{\mathrm{cr}}=1.125 \omega_{\mathrm{c}} \\
& \omega_{\mathrm{cl}}=0.875 \omega_{\mathrm{c}}
\end{aligned}
$$

thus confirming that the right-hand clutch is 'speeded up' relative to the differential cage and the left-hand clutch is slowed down. It therefore follows that, if the right-hand clutch is locked

$$
\omega_{\mathrm{r}}=\omega_{\mathrm{cr}}=1.125 \omega_{\mathrm{c}}
$$

and to satisfy equation (60), the left-hand wheel speed must be

$$
\omega_{1}=2 \omega_{\mathrm{c}}-1.125 \omega_{\mathrm{c}}=0.875 \omega_{\mathrm{c}}
$$

If the vehicle is considered to be travelling in a straight line, so that initially $\omega_{\mathrm{l}}=\omega_{\mathrm{r}}=\omega_{\mathrm{c}}$, it can thus be seen that the right-hand wheel will be speeded up by 12.5 per cent while the left-hand wheel will be slowed down by 12.5 per cent.

It is thus clear that the maximum wheel speed difference that can be generated with these gear ratios is 25 per cent. Provided the wheel speed difference falls within this range, it is possible to control which wheel is speeded up and which is slowed down by selectively operating the two clutches.

The relationship between the torque transfer at the clutches and the torque transfer between the wheels can be illustrated via separate analysis of torque balances across the three-gang gearing, the differential gearing, and the differential case respectively (Fig. 1). Consider engagement of the right-hand clutch alone; a torque introduced at this clutch plate, $\Delta T_{\mathrm{cr}}$, will induce a reaction torque, through the three-gang gearing, on the differential case $T_{x}$, with the relationship

$$
\frac{z_{4}}{z_{1}} T_{x}-\frac{z_{5}}{z_{2}} \Delta T_{\mathrm{cr}}=0
$$

Because the bevel gears of the differential will always supply an equal amount of torque to their left- and right-hand output shafts

$$
T_{1}=T_{\mathrm{r}}-\Delta T_{\mathrm{cr}}
$$

These relationships can then be combined with a torque balance on the differential case

$$
T_{\mathrm{i}}-T_{x}-T_{1}-\left(T_{\mathrm{r}}-\Delta T_{\mathrm{cr}}\right)=0
$$

to give

$$
T_{1}=\frac{T_{\mathrm{i}}}{2}-\frac{z_{1} z_{5}}{2 z_{4} z_{2}} \Delta T_{\mathrm{cr}}
$$

A similar rearrangement of these equations can then be used to yield the following expression for the right-hand wheel torque

$$
T_{\mathrm{r}}=\frac{T_{\mathrm{i}}}{2}+\left(1-\frac{z_{1} z_{5}}{2 z_{4} z_{2}}\right) \Delta T_{\mathrm{cr}}
$$

and substituting the tooth numbers shown in Table 4 gives

$$
\begin{aligned}
& T_{1}=\frac{T_{\mathrm{i}}}{2}-0.5625 \Delta T_{\mathrm{cr}} \\
& T_{\mathrm{r}}=\frac{T_{\mathrm{i}}}{2}+0.4375 \Delta T_{\mathrm{cr}}
\end{aligned}
$$

It can thus be seen that an overdriven differential removes more torque from one wheel than it adds to the other, and that the total torque flowing to the wheels is reduced according to

$$
T_{1}+T_{\mathrm{r}}=T_{\mathrm{i}}+\left(1-\frac{z_{1} z_{5}}{z_{2} z_{4}}\right) \Delta T_{\mathrm{cr}} \Rightarrow T_{\mathrm{i}}-0.125 \Delta T_{\mathrm{cr}}
$$

The difference in the torque applied to the two wheels is still, however, simply the clutch torque

$$
T_{1}-T_{\mathrm{r}}=-\Delta T_{\mathrm{cr}}
$$

Clutch torque capacities in excess of $1000 \mathrm{~N} \mathrm{~m}$ are feasible [2]. Note that this represents the maximum torque difference that can be achieved. The actual torque difference that can be achieved at any given time is the torque that is required to lock the clutch pack. This may well be less than the clutch torque capacity when, for example, the vehicle is on a low $\mu$ surface. 
A similar analysis of the torque balance during left-hand clutch engagement yields the following expressions for left-hand, right-hand, and total wheel torques

$$
\begin{aligned}
& T_{1}=\frac{T_{\mathrm{i}}}{2}+\frac{z_{1} z_{6}}{2 z_{3} z_{4}} \Delta T_{\mathrm{cl}} \Rightarrow \frac{T_{\mathrm{i}}}{2}+0.4375 \Delta T_{\mathrm{cl}} \\
& T_{\mathrm{r}}=\frac{T_{\mathrm{i}}}{2}-\left(1-\frac{z_{1} z_{6}}{2 z_{3} z_{4}}\right) \Delta T_{\mathrm{cl}} \Rightarrow \frac{T_{\mathrm{i}}}{2}-0.5625 \Delta T_{\mathrm{cl}} \\
& T_{1}+T_{\mathrm{r}}=T_{\mathrm{i}}-\left(1-\frac{z_{1} z_{6}}{z_{3} z_{4}}\right) \Delta T_{\mathrm{cl}} \Rightarrow T_{\mathrm{i}}-0.125 \Delta T_{\mathrm{cl}}
\end{aligned}
$$

$$
T_{1}-T_{\mathrm{r}}=\Delta T_{\mathrm{cl}}
$$

Although no advantage is to be gained from engaging both clutches simultaneously, delays in the actuator time response make such a scenario possible. Combining equations (68) and (74) (for the left-hand side) and equations (69) and (75) (for the right-hand side) therefore gives the complete expression for wheel torque

$$
\begin{aligned}
& T_{1}=\frac{T_{\mathrm{i}}}{2}-\frac{z_{1} z_{5}}{2 z_{4} z_{2}} \Delta T_{\mathrm{cr}}+\frac{z_{1} z_{6}}{2 z_{3} z_{4}} \Delta T_{\mathrm{cl}} \\
& T_{\mathrm{r}}=\frac{T_{\mathrm{i}}}{2}+\left(1-\frac{z_{1} z_{5}}{2 z_{4} z_{2}}\right) \Delta T_{\mathrm{cr}}-\left(1-\frac{z_{1} z_{6}}{2 z_{3} z_{4}}\right) \Delta T_{\mathrm{cl}}
\end{aligned}
$$

Note that these equations show that, as with a conventional differential, control over the lateral torque difference at the wheels is independent of engine torque. 